University of South Carolina

Scholar Commons

2-1-2009

\title{
Correlating Threshold Power with Free-Space Bandwidth for Low- Directivity Antennas
}

\author{
Abu T.M. Sayem \\ Motorola, Inc., abu.sayem@motorola.com \\ Mark G. Douglas \\ Motorola, Inc., mark.douglas@motorola.com \\ Gernot Schmidt \\ Austrian Research Centers GmbH-ARC, gernot.schmid@arcs.ac.at \\ Ben Petric \\ Austrian Research Centers GmbH-ARC \\ Mohammod Ali \\ University of South Carolina - Columbia, alimo@engr.sc.edu
}

Follow this and additional works at: https://scholarcommons.sc.edu/elct_facpub

Part of the Electrical and Computer Engineering Commons

Publication Info

Published in IEEE Transactions on Electromagnetic Compatibility, Volume 51, 2009, pages 25-37. http://ieeexplore.ieee.org/xpl/Recentlssue.jsp?punumber=15

(C) 2009 by IEEE

This Article is brought to you by the Electrical Engineering, Department of at Scholar Commons. It has been accepted for inclusion in Faculty Publications by an authorized administrator of Scholar Commons. For more information, please contact digres@mailbox.sc.edu. 


\title{
Correlating Threshold Power With Free-Space Bandwidth for Low-Directivity Antennas
}

\author{
Abu T. M. Sayem, Mark G. Douglas, Senior Member, IEEE, Gernot Schmid, Ben Petric, \\ and Mohammod Ali, Senior Member, IEEE
}

\begin{abstract}
This paper develops a threshold power rationale that can be used to demonstrate inherent compliance for portable wireless devices with specific absorption rate (SAR) limits over the 3006000-MHz frequency range. This is achieved first by understanding the relationship between basic antenna parameters (bandwidth, operating frequency, and distance to the body) and SAR. From this, an upper limit is determined for the power transmitted by a portable wireless device such that the SAR will not exceed the compliance limit. Based on the presented computational and measured data, an empirical formula is developed for the threshold power as a function of the aforementioned parameters. It is demonstrated that the derived threshold power is conservative for all of the lowdirectivity antennas studied. Computed results are also compared against practical device data (mobile telephone data collected from the manufacturers) to show that the predicted threshold power data using the proposed formula are conservative. The limitations of the proposed formula are also discussed.
\end{abstract}

Index Terms-Antenna measurements, antennas, electromagnetic propagation in absorbing media, numerical analysis.

\section{INTRODUCTION}

$\mathbf{P}$ ORTABLE wireless devices, such as cellular telephones and two-way radios, are routinely tested for compliance with specific absorption rate (SAR) limits [1]. Compliance is typically demonstrated by performing measurements using automated systems in phantoms representing the human body [2], [3]. SAR can also be computed using numerical electromagnetic modeling techniques, such as the finite-difference time-domain (FDTD) method [4]. The measured or computed SAR values are compared with SAR limits for the applicable country, which, for general public exposure at the head or torso, are either $1.6 \mathrm{~W} / \mathrm{kg}$ averaged over a 1 -g tissue mass [5] or $2 \mathrm{~W} / \mathrm{kg}$ averaged over $10 \mathrm{~g}$ [6], [7]. Measurement or numerical modeling can be expensive and time-consuming to perform. Moreover, some devices transmit at very low output powers or are used far from the user's body. It would be useful to categorize such devices as inherently

Manuscript received October 4, 2007; revised April 30, 2008. First published November 7, 2008; current version published February 13, 2009. This work was supported by the Mobile Manufacturers Forum, Brussels, Belgium, and the GSM Association, London, U.K.

A. T. M. Sayem was with the University of South Carolina, Columbia, SC 29208 USA. He is now with Motorola, Inc., Libertyville, IL 60048 USA (e-mail: abu.sayem@motorola.com).

M. G. Douglas is with Motorola, Inc., Fort Lauderdale, FL 33322 USA (e-mail: mark.douglas@motorola.com).

G. Schmid and B. Petric are with the Austrian Research Centers GmbH-ARC, Seibersdorf A-2444, Austria (e-mail: Gernot.Schmid@arcs.ac.at).

M. Ali is with the University of South Carolina, Columbia, SC 29208 USA (e-mail: alimo@engr.sc.edu).

Color versions of one or more of the figures in this paper are available online at http://ieeexplore.ieee.org.

Digital Object Identifier 10.1109/TEMC.2008.2004052 compliant with the SAR limits, based on a robust scientific rationale. That is the aim of this paper. It is also the subject of a draft IEC standard [8]. A previous standard [9] categorizes devices as inherently compliant with the $2 \mathrm{~W} / \mathrm{kg}$ SAR limit if the transmitted power is below $20 \mathrm{~mW}$. This simple threshold does not take into account parameters such as frequency, distance, or bandwidth. In addition, it assumes that all of the power is absorbed in the 10-g tissue mass and none is used for communication, as explained in [10].

In the literature, there has been considerable research on antennas and SAR. Kuster and Balzano [11] studied the basic mechanisms that influence the SAR and found that the SAR distribution is strongly related to the current distribution on the antenna. Jensen and Rahmat-Samii [12] and Okoniewski and Stuchly [13] investigated the interaction between the antenna and the body, including how the presence of the user affects the antenna efficiency. Analyses of the influence of the head model on SAR by Hombach et al. [14] and Meier et al. [15] found that homogeneous phantoms can give a good representation of the SAR in a person. Watanabe et al. [16] analyzed the influence of the head and hand models on SAR at different distances from dipole and monopole antennas. Other investigations of the influence of antenna and body parameters on SAR have been performed on specific antenna types, such as linear wire antennas [17]-[19], helices [20]-[23], and planar antennas [24]-[27]. There have also been studies to develop and improve measurement and computational methods [3], [20], [28], [29] and to analyze human head and body models [30]-[33].

Interestingly, to date, there has been no report in the literature that attempts to relate one or more antenna performance characteristics (e.g., bandwidth or directivity) to SAR over several categories of antennas. Due to the expense of measurements and numerical modeling, developing this relationship can lead to much easier and cost-effective estimates of SAR for portable wireless devices. Recently, the authors investigated such a relationship for linear wire dipole antennas [10]. The paper defined a minimum threshold power level below which the SAR cannot exceed the SAR limit. Kivekäs et al. [26] explored a relationship between bandwidth, efficiency, and SAR for one planar antenna at each of two frequencies. The agreement of our results with this paper will be discussed later.

Most portable wireless devices generally operate very close to the user's head or body (about 5-25 $\mathrm{mm}$ from the head or body) within the $300 \mathrm{MHz}$ to $6 \mathrm{GHz}$ frequency range. At these distances and frequencies, the user is typically in the near field of the antennas [34]. Since the quality factor $(Q)$ of an antenna is a function of its stored and radiated energies [35], it is expected 
that there may exist an inherent relationship between the antenna $Q$ (and therefore, the impedance bandwidth) and the maximum SAR it will induce into a human head or body.

The primary focus of this paper is to study the performance characteristics and SAR of a large number of antennas over a wide frequency range in order to explore the possibility of developing such a relationship. To that end, we investigate dipoles, monopoles, planar inverted-F antennas (PIFAs), inverted-F antennas (IFAs), and microstrip patches in the frequency range of $300-6000 \mathrm{MHz}$, both in free space and next to a flat phantom. The antennas selected in this paper have radiation characteristics that are representative of a large majority of portable wireless transmitters. They may not be representative of highly directional antennas, such as those employed in indoor/outdoor fixed transmitters, but such devices, which are not intended to operate near the user's head or body, are out of the scope of this paper.

The paper is organized as follows. First, the antenna geometrical models and the computational and measurement methods are described. Second, a summary of the simulation and measurements results are presented and explained. Third, based on these results, a statistical analysis of all simulation and measurement data is performed to develop a formula that can be used to estimate the threshold power conservatively. Finally, the validity of the formula is demonstrated by comparing the predicted threshold power with that obtained from direct simulation and measurement.

\section{Methodology}

\section{A. Antenna Models}

A large variety of antenna types, shapes, and sizes are used in wireless devices. Performing a study that includes all antenna types, shapes, and sizes is a formidable task and is not required since many of them have similar impedance, bandwidth, efficiency, and gain characteristics. A better approach is to categorize the antennas into broad classes and analyze representative antennas from each class. In this paper, we have classified commonly used antennas into dipoles, monopoles, PIFAs, IFAs, and microstrip patches. All measured antennas are externally fed via coaxial cables. Quarter-wavelength baluns are used to choke off antenna currents.

For all calculations and measurements performed in this study, the antenna is positioned next to a flat phantom (see Fig. 1). The flat phantom consists of a lossy phantom material and a lossless outer shell having a relative permittivity of 3.7. The dielectric parameters and the minimum dimensions of the phantom material, and the $2 \mathrm{~mm}$ thickness of the outer shell meet the specifications of IEEE Standard 1528-2003 [36] and the latest draft of IEC 62209-2 [37].

The dielectric parameters of the phantom material were established to produce a SAR in the head that is conservatively high when compared to real people [36], [38]. Independent studies have confirmed that the dielectric parameters are conservative for the head [32], [33]. The results of Christ et al. [39] and the analysis of Douglas and Chou [40] show that the SAR is conservatively high in the phantom when these head dielectric

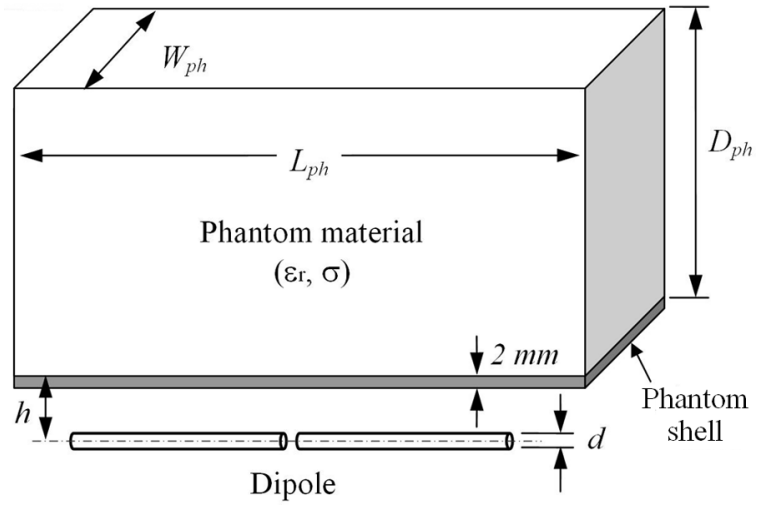

Fig. 1. Schematic of antenna position next to the flat phantom. $h$ is the distance from the phantom material to the antenna feedpoint on the dipole axis. The minimum length $\left(L_{\mathrm{ph}}\right)$, width $\left(W_{\mathrm{ph}}\right)$, and depth $\left(D_{\mathrm{ph}}\right)$ of the phantom, and the dielectric parameters $\left(\varepsilon_{r}, \sigma\right)$ of the phantom material comply with [36] and [37].

parameters are used instead of the dielectric parameters for the trunk of the body adopted by the U.S. Federal Communications Commission guidelines [41]. IEC 62209-2 has therefore adopted the use of head dielectric parameters for the trunk of the body also. Additionally, it has been shown by Okoniewski and Stuchly [13] that a flat phantom has a significantly higher SAR than a spherical or a realistic human head phantom. For these reasons, the flat phantom analysis presented in this paper provides conservative results that are applicable to both head and body exposure.

1) Dipole Antennas: Linear wire dipole antennas of lengths $\lambda / 15, \lambda / 8, \lambda / 4$, and $\lambda / 2$ were studied at $300,450,900,1450$, $1900,2450,3700$, and $6000 \mathrm{MHz}$ in free space and next to the flat phantom. The distances between the antenna feedpoint and the phantom material are $h=5,10$, and $20 \mathrm{~mm}$ (see Fig. 1). The dipole wire radius is $1.8 \mathrm{~mm}$.

2) Monopole Antennas: Quarter-wave linear monopole antennas at 300, 900, 1900,3700, and $6000 \mathrm{MHz}$ were mounted on the center of the top face of a $100 \times 40 \times 19 \mathrm{~mm}^{3}$ metal box resembling a conventional portable wireless device [see Fig. 2(a)]. Helical monopoles (14 turns, 48-mm axial length, $4 \mathrm{~mm}$ diameter) and printed meander monopoles $(7 \mathrm{~mm}$ pitch and $51-\mathrm{mm}$ axial length, printed on RO 4003 c substrate), both operating at $900 \mathrm{MHz}$, were also investigated. A dual-band meander antenna operating at 900 and $1900 \mathrm{MHz}$ was also analyzed [see Fig. 2(b)]. The meandered branch is responsible for the resonance at the low frequency while the straight strip is responsible for the resonance at the high frequency. Antennas were studied in free space and next to the flat phantom $(h=12$ and $20 \mathrm{~mm})$. Due to the thickness of the metal box and the phantom shell, the smallest distance that could be used was $h=12 \mathrm{~mm}$.

3) Planar Antennas: All planar antenna models were mounted on a metal box of dimensions $100 \times 40 \times 10 \mathrm{~mm}^{3}$. They were modeled and measured both in free space and next to the phantom. Next to the phantom, the antennas were oriented in both the conventional [Fig. 3(a)] and flipped orientations [Fig. 3(b)]. In the flipped orientation, the smallest distance to the phantom was $h=10 \mathrm{~mm}$, whereas in the conventional 


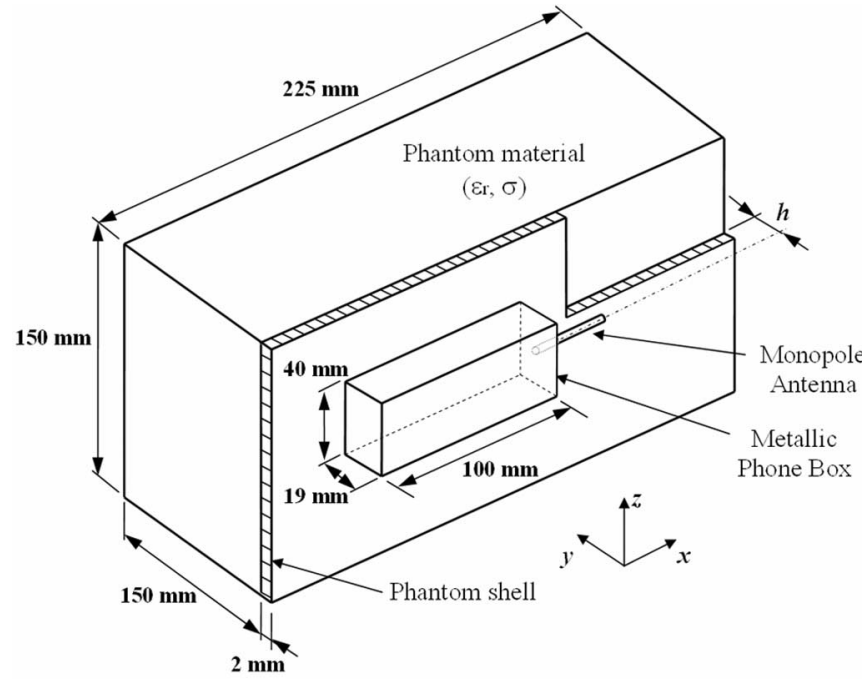

(a)

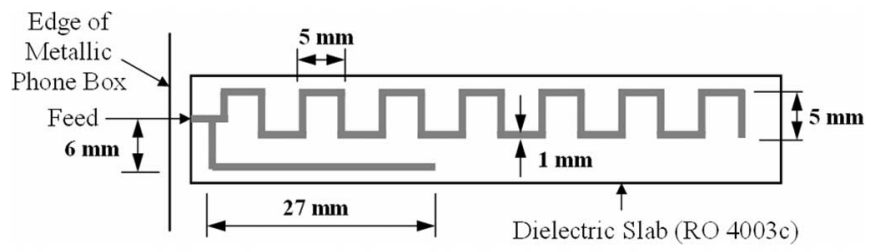

(b)

Fig. 2. (a) Monopole antenna mounted on a metal box positioned next to a flat phantom and (b) geometry of a dual-band meander monopole antenna operating at 900 and $1900 \mathrm{MHz}$. The flat phantom dimensions are shown for frequencies of $900 \mathrm{MHz}$ and above, according to [36] and [37]. $h$ is the distance from the phantom material to the antenna feedpoint.

orientation, the smallest distance was $h=13 \mathrm{~mm}$ due to the thickness of the metal box. A distance of $h=20 \mathrm{~mm}$ was also used for both orientations.

PIFAs at heights of $6 \mathrm{~mm}$ or higher from the ground plane are widely used for portable wireless devices at 900 and $1900 \mathrm{MHz}$ [42]. Hence, two specific PIFAs at this height and these two frequencies were chosen for the study. Fig. 4(a) shows the schematic for these antennas. The width $(W)$ and length $(L)$ of the antenna are $31 \mathrm{~mm}$ and $40 \mathrm{~mm}$ at $900 \mathrm{MHz}$ and $13.5 \mathrm{~mm}$ and $20 \mathrm{~mm}$ at $1900 \mathrm{MHz}$. The feed and the shorting pin were constructed from 1-mm-wide strips and were separated from each other by $2.5 \mathrm{~mm}$ at $900 \mathrm{MHz}$ and $2 \mathrm{~mm}$ at $1900 \mathrm{MHz}$, respectively.

Two surface mount PIFAs operating at 2450 and $3700 \mathrm{MHz}$ were also studied. The geometry of the surface mount PIFA is shown in Fig. 4(b). A 3-mm-thick FR4 substrate was placed on top of the metal box as shown. For both frequencies, the trace width $(W)$ is $1 \mathrm{~mm}$. Antenna lengths $(L)$ are $16.5 \mathrm{~mm}$ at $2450 \mathrm{MHz}$ and $9.75 \mathrm{~mm}$ at $3700 \mathrm{MHz}$. The feed to shorting pin distance $(x)$ is $1 \mathrm{~mm}$ at $2450 \mathrm{MHz}$ and $0.5 \mathrm{~mm}$ at $3700 \mathrm{MHz}$. The loss tangent of FR4 is 0.02 .

An IFA, as described in [43], was designed for operation at $2450 \mathrm{MHz}$. To ensure that there is no metal ground under the antenna, metal was removed from the handset box with a volume of $20 \times 5 \times 10 \mathrm{~mm}^{3}$, as illustrated in Fig. 4(c).
Generally microstrip patch antennas are not used in commercial portable wireless devices at frequencies below $2000 \mathrm{MHz}$ because of their relatively large size and narrow bandwidth. In this study, microstrip patches operating at 2450, 3700 and $6000 \mathrm{MHz}$ were investigated. The antenna geometry and its placement location with respect to the metal box are shown in Fig. 4(d). The antenna dimensions $(W \times L)$ are $36.5 \mathrm{~mm} \times$ $27.5 \mathrm{~mm}, 24.0 \mathrm{~mm} \times 17.5 \mathrm{~mm}$ and $15.0 \mathrm{~mm} \times 11.0 \mathrm{~mm}$ at $2450 \mathrm{MHz}, 3700 \mathrm{MHz}$, and $6000 \mathrm{MHz}$, respectively. The feedpoint inset $(y)$ is $6.25 \mathrm{~mm}, 4.0 \mathrm{~mm}$, and $1.0 \mathrm{~mm}$, respectively.

Finally, two dual-band PIFAs operating at 900 and $1900 \mathrm{MHz}$ and 2450 and $6000 \mathrm{MHz}$ and one dual band IFA operating at 2450 and $6000 \mathrm{MHz}$ were studied. Fig. 4(e)-(g) show the respective antenna geometrical models and dimensions.

\section{B. Computational Techniques}

For this paper, BW is used to denote the half-power bandwidth of the antenna in free space. To provide a conservatively high value of bandwidth, a perfect impedance match condition was enforced at the center frequency during postprocessing. In this condition, the half-power bandwidth is approximately equal to $1 / Q$ and corresponds to $\left|S_{11}\right| \leq-7 \mathrm{~dB}$ (i.e., voltage standing wave ratio of 2.6 or less) [44], [45]. The bandwidth is determined with the antenna in free space (i.e., the phantom is not present), and is expressed as a percentage of the center frequency. The reason for choosing the free-space bandwidth is because it is easier to measure than when it is near the phantom, it is well known by the device manufacturer, and it is independent of the user configuration (used at the head, worn on the belt, etc.).

Antenna efficiency was computed next to the flat phantom. Since there is no mismatch loss, the antenna efficiency is equal to the radiation efficiency and accounts for the dielectric losses in the phantom material and the antenna substrate, if any.

Peak 1-g and 10-g averaged SAR values were computed using an antenna transmit power of $1 \mathrm{~W}$ rms. Since some antennas in this study are not resonant, much of the power would normally be reflected at the antenna feedpoint. However, a perfect impedance match was enforced, resulting in conservatively high SAR values. In accordance with [36] and [37], the flat phantom dimensions are $600 \times 400 \times 150 \mathrm{~mm}^{3}$ for frequencies of 300 and $450 \mathrm{MHz}$ and $225 \times 150 \times 150 \mathrm{~mm}^{3}$ for higher frequencies.

A commercial method of moments program (IE3D, Zeland Software, Freemont, CA, USA) [46] was used to compute the bandwidth and efficiency of the dipole antennas. The phantom was modeled as in Fig. 1. To save computation time without sacrificing accuracy, the shell and phantom material were modeled as infinite dielectric slabs with finite depth $(2 \mathrm{~mm}$ for the shell and $150 \mathrm{~mm}$ for the phantom material) and infinite length and width.

For the monopole and planar antennas, a commercial FDTD program (XFDTD, Remcom Inc., State College, PA, USA) was used for all bandwidth, efficiency, and SAR calculations [47]. XFDTD was also used for SAR calculations of the dipole antennas. In an earlier paper [10], the XFDTD models were validated against the half-wave dipole data presented in IEEE Standard 1528-2003 [36]. In this paper, we used the Liao absorbing 

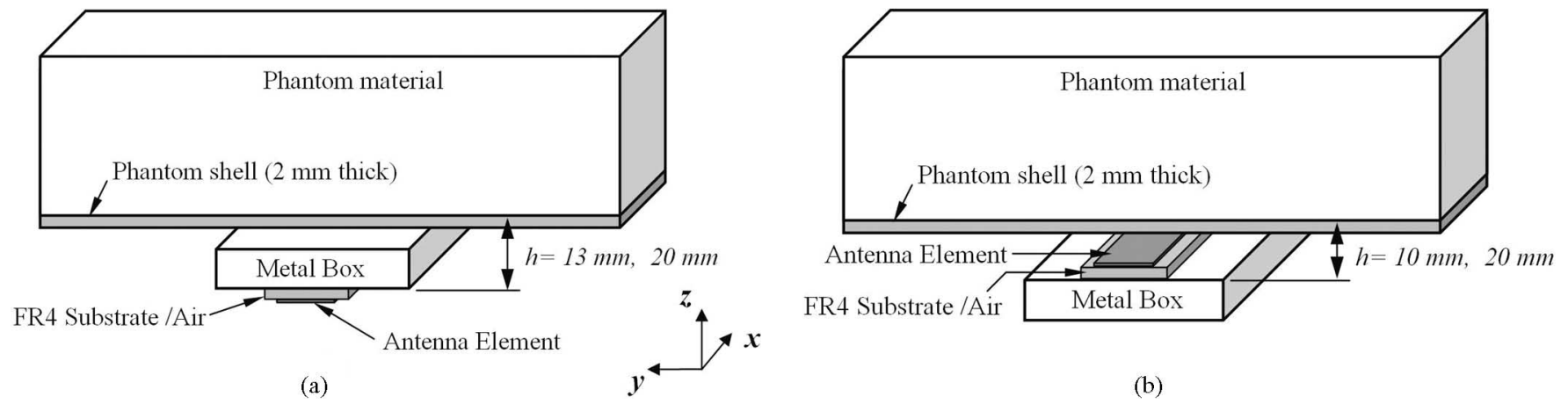

(b)

Fig. 3. Representation of the antenna with respect to the phantom in the (a) conventional orientation and (b) flipped orientation. $h$ is the distance from the phantom material to the antenna feedpoint, regardless of the antenna orientation.

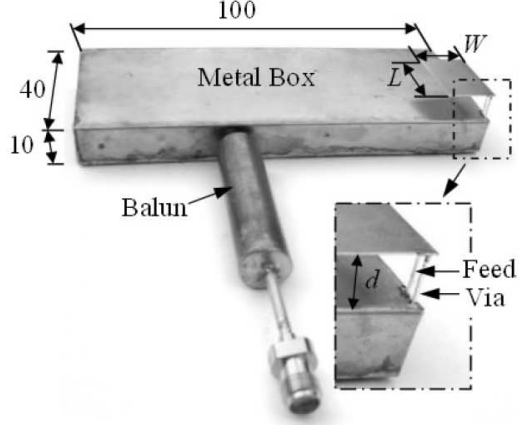

(a)

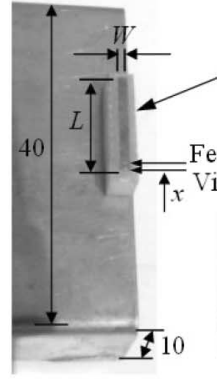

(b)

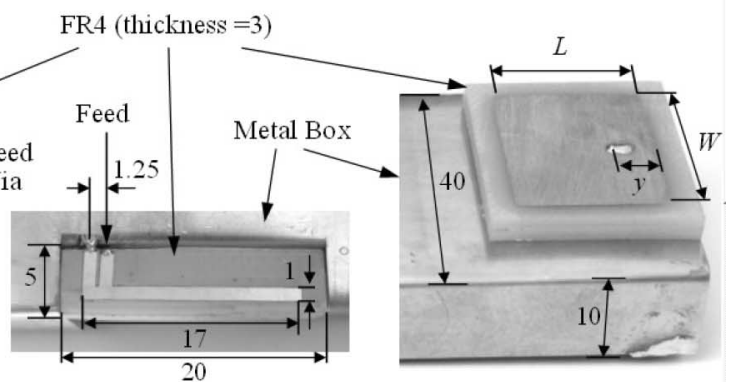

(c) (d)

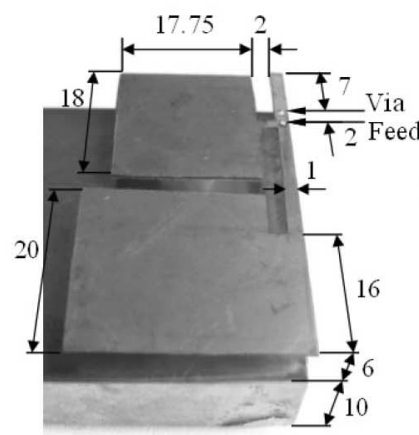

(e)

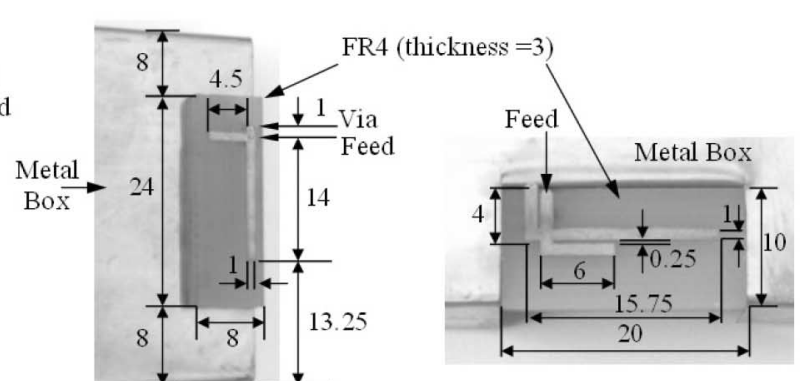

(f)

(g)

Fig. 4. Experimental prototypes of (a) PIFA, (b) surface mount PIFA, (c) surface mount IFA, (d) microstrip patch, (e) dual-band PIFA, (f) dual-band surface mount PIFA, and (g) dual-band surface mount IFA (all dimensions are in millimeters).

boundary condition $(\mathrm{ABC})$ to save computation time. The efficacy of the Liao $\mathrm{ABC}$ was verified by comparing with perfectly matched layer (PML) ABC data. For impedance computations, Gaussian pulses were used with automatic convergence at a threshold of $-40 \mathrm{~dB}$. For SAR and efficiency computations, a sinusoidal waveform was used. Generally, a uniform mesh of $1 \mathrm{~mm}$ was used, while for the planar antennas, a graded mesh was selected with the mesh size ranging between a minimum of $0.25 \mathrm{~mm}$ and a maximum of $1 \mathrm{~mm}$.

\section{Measurement Techniques}

Measurements were performed for a selected number of antennas from the full set that were analyzed with computational techniques. For measuring the impedance bandwidth of the an- tenna models, the complex $S_{11}$ parameter in the frequency range $100 \mathrm{MHz}$ to $10 \mathrm{GHz}$ was measured and recorded using an 8722 $\mathrm{C}$ vector network analyzer (Agilent, Santa Clara, CA, USA) after standard open-short-load calibration. From the recorded $S_{11}$ versus frequency data, the bandwidth was computed after enforcing a perfect match at the desired frequency.

SAR measurements were carried out with the antenna models positioned next to the elliptical flat phantom ELI4 with major and minor axes of approximately $600 \mathrm{~mm}$ and $400 \mathrm{~mm}$ (Schmid \& Partner Engineering AG, Zürich, Switzerland). Approximately $28 \mathrm{~L}$ of tissue-equivalent liquid yield a phantom material depth of $150 \mathrm{~mm}$. The phantom size and dielectric properties of the phantom liquid correspond to [36] and [37]. The dielectric properties of the liquids were measured prior to SAR measurements using the HP85070B dielectric probe kit in 


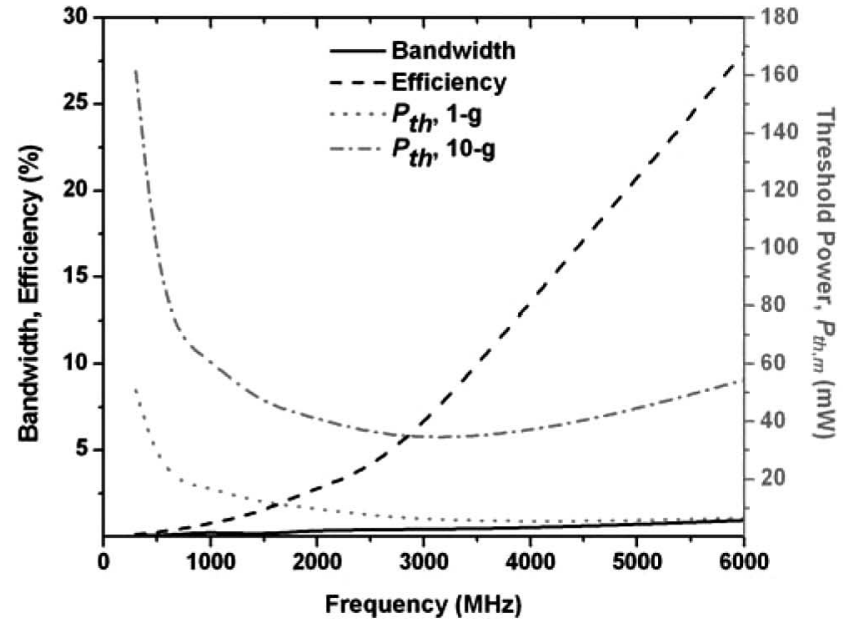

(a)

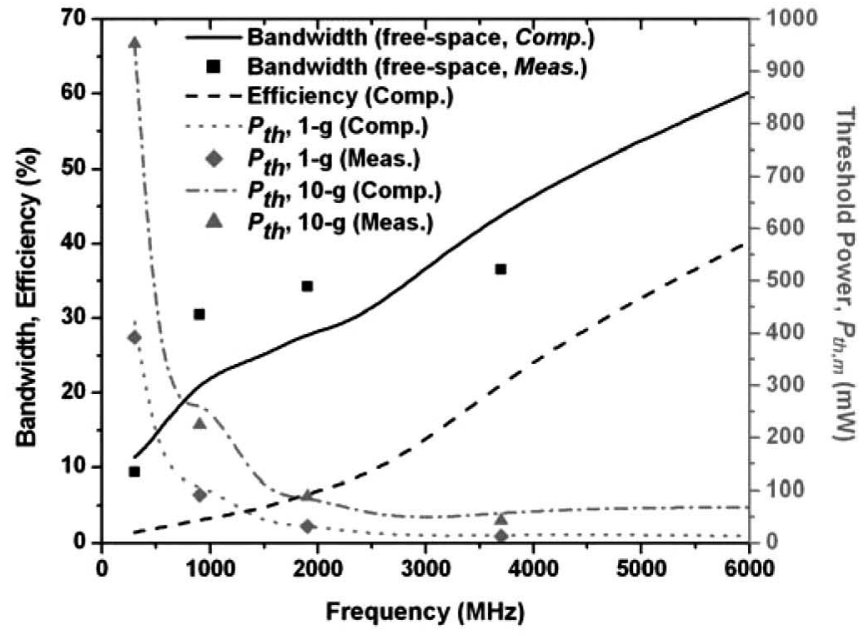

(b)

Fig. 5. Half-power bandwidth in free-space, efficiency, and threshold power of (a) $\lambda / 15$ dipoles at $h=5 \mathrm{~mm}$ and (b) $\lambda / 2$ dipoles at $h=5 \mathrm{~mm}$.

combination with the vector network analyzer. In the case of deviations from the target values of more than $\pm 5 \%$, the liquids were adjusted and remeasured. SAR measurements were conducted using the DASY3 system from Schmid \& Partner Engineering AG. The uncertainty assessments for the SAR measurements according to IEEE Standard 1528-2003 yielded a $\pm 25 \%-30 \%$ expanded $(k=2)$ measurement uncertainty, depending on frequency.

\section{RESULTS}

\section{A. Bandwidth, Efficiency, and Threshold Power}

In a previous paper, the authors defined a quantity called the threshold power, $P_{\mathrm{th}, m},[10]$ which represents the antenna transmit power at which the peak spatial-averaged SAR has reached the applicable SAR limit. Thus, according to [10, eq. (3)]

$$
P_{\mathrm{th}, m}=\frac{P_{t} \mathrm{SAR}_{\text {limit }, m}}{\mathrm{SAR}_{m}}
$$

where $P_{t}$ is the transmit power ( $1 \mathrm{~W}$ in this study), $\mathrm{SAR}_{m}$ is the computed or measured peak SAR averaged over tissue mass $m$ (either $1 \mathrm{~g}$ or $10 \mathrm{~g}$ ) and $\mathrm{SAR}_{\text {limit }, m}$ is either $1.6 \mathrm{~W} / \mathrm{kg}$ for $m=1 \mathrm{~g}$ [5], or $2 \mathrm{~W} / \mathrm{kg}$ for $m=10 \mathrm{~g}$ [6], [7]. The next three sections show the results for the three main antenna classes: dipoles, monopoles, and planar antennas.

1) Dipole Antennas: Since the number of antennas and other variables in this paper is large, a selected number of cases is presented to elucidate the observations. In Fig. 5, bandwidth, efficiency, and $P_{\mathrm{th}, m}$ for $\lambda / 15$ and $\lambda / 2$ dipoles are shown for a distance of $h=5 \mathrm{~mm}$. For the $\lambda / 15$ dipoles, Fig. 5(a) shows that the maximum value of $B W$ is $0.1 \%$ at $300 \mathrm{MHz}$ and $0.96 \%$ at $6000 \mathrm{MHz}$. The physically small antenna to phantom distance translates into a very small electrical distance at the lower frequencies that results in minimal useful radiated power, as nearly all of the power is absorbed in the phantom. Although bandwidth increases with frequency, the largest value is still quite inadequate for most practical applications. It is therefore unnecessary to analyze dipole antennas with lengths shorter than $\lambda / 15 . P_{\mathrm{th}, m}$ for $m=1 \mathrm{~g}$ and $10 \mathrm{~g}$ are also shown in Fig. 5(a). As expected, $P_{\mathrm{th}, m}$ is large at the low frequencies partly due to the low conductivity of the medium. The smallest $P_{\mathrm{th}, m}$ value is $5.6 \mathrm{~mW}$ for $1 \mathrm{~g}$ average and $35.8 \mathrm{~mW}$ for $10 \mathrm{~g}$ average, both at $3700 \mathrm{MHz}$. Similar data are also plotted in Fig. 5(b) for the $\lambda / 2$ dipole antennas. Simulated and measured BW data are generally in good agreement. BW numbers are significantly larger than those for the $\lambda / 15$ antennas, as expected [35], increasing from $11.4 \%$ to $60.2 \%$ with frequency. Antenna efficiency is greater than that of the $\lambda / 15$ antennas but has the same general trend. Comparing the $P_{\mathrm{th}, m}$ scales of Fig. 5(a) and (b), it is clear that $P_{\mathrm{th}, m}$ is higher for the $\lambda / 2$ antennas than the $\lambda / 15$ antennas, the highest being $421 \mathrm{~mW}$ versus $50 \mathrm{~mW}$ for $m=1 \mathrm{~g}$.

2) Monopole Antennas: Computed and measured BW and $P_{\mathrm{th}, m}$ for quarter-wave linear monopole antennas are compared in Fig. 6. The computed and measured BW data in Fig. 6(a) are in good agreement. Bandwidth is highest at $900 \mathrm{MHz}$ because the combined length of the handset and the monopole is close to a half-wavelength at $900 \mathrm{MHz}$, making the structure selfresonant.

Fig. 6(b) and (c) illustrate the computed and measured $P_{\mathrm{th}, m}$ data as a function of frequency. The agreement between the simulated and measured data is excellent. As apparent, for both the 1-g and 10-g average cases and for both $h=12 \mathrm{~mm}$ and $h=$ $20 \mathrm{~mm}, P_{\mathrm{th}, m}$ decreases sharply at the lower frequencies up to $900 \mathrm{MHz}$. At lower frequencies, the spacings of 12 and $20 \mathrm{~mm}$ are electrically small, and therefore, the antenna demonstrates near-field behavior (increasing SAR or decreasing $P_{\mathrm{th}, m}$ with frequency). As the frequency increases, the electrical distance increases, and hence, $P_{\mathrm{th}, m}$ is either monotonic or increases slightly with frequency.

A quarter-wave linear monopole, a meander monopole, and a helical monopole are compared in Table I. All three antennas are operating at $900 \mathrm{MHz}$. Since the helical and meander monopoles have shorter axial lengths, their bandwidths are narrower than the quarter-wave linear monopole [35]. A shorter axial length 


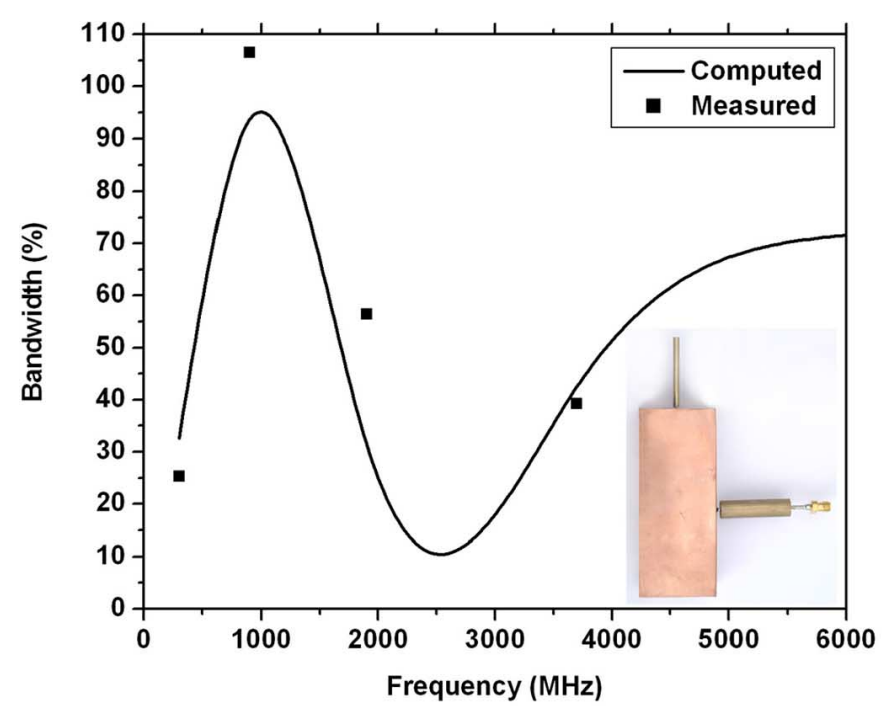

(a)

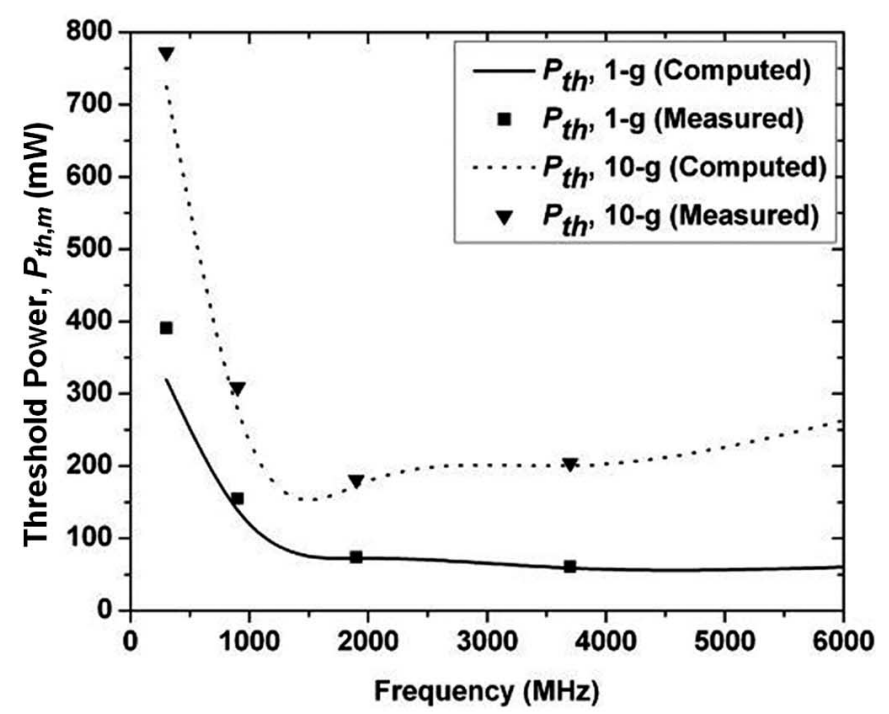

(b)

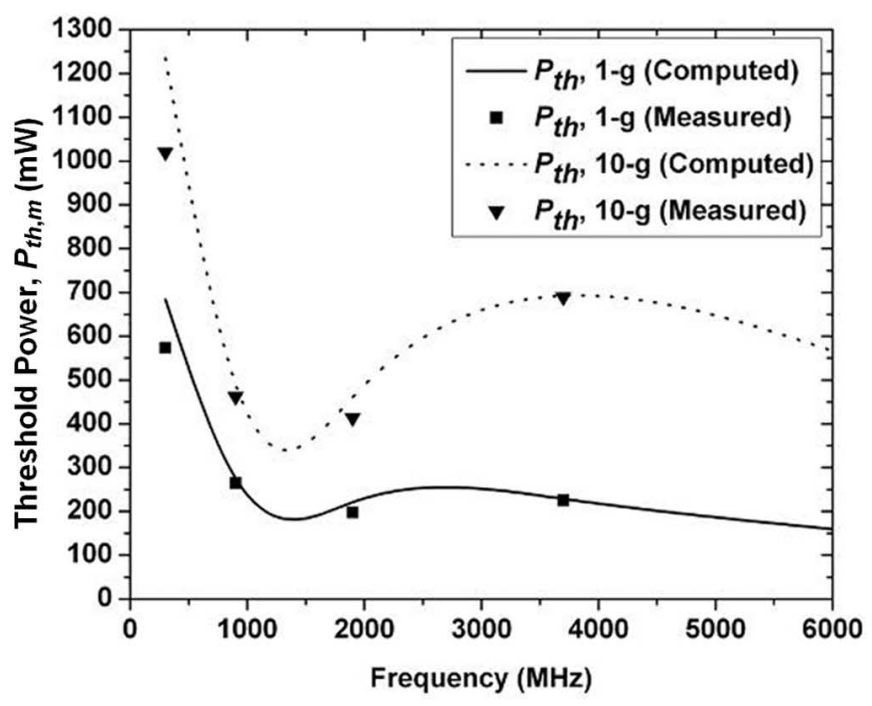

(c)

Fig. 6. (a) Half-power bandwidth in free space, (b) threshold power at $h=$ $12 \mathrm{~mm}$, and (c) threshold power at $h=20 \mathrm{~mm}$ of linear monopole antennas.
TABLE I

COMPARISON OF BANDWIDTH, EFFICIENCY, AND THRESHOLD POWER OF MONOPOLE ANTENNAS AT $f=900 \mathrm{MHz}$ AND $h=12 \mathrm{~mm}$

\begin{tabular}{lccc}
\hline \hline Antennas & Linear Monopole & Meander Monopole & Helical Monopole \\
\hline BW (Computed), \% & N/4, AL $=81 \mathrm{~mm}$ & $\mathrm{AL}=51 \mathrm{~mm}$ & $\mathrm{AL}=48 \mathrm{~mm}$ \\
\hline BW (Measured), \% & 93.7 & 49.5 & 45.8 \\
\hline Efficiency (Computed), \%* & 106.5 & 63.7 & 48.2 \\
\hline$P_{t h, 1 g},($ Computed), $\mathrm{mW}$ & 6.2 & 7.2 & 6.8 \\
\hline$P_{t h, 1 g},($ Measured), $\mathrm{mW}$ & 139.0 & 125.8 & 105.0 \\
\hline$P_{t h, 10 \mathrm{~g},},($ Computed), $\mathrm{mW}$ & 155.0 & 131.0 & 119.0 \\
\hline$P_{t h, 10 g},($ Measured), $\mathrm{mW}$ & 278.2 & 258.7 & 222.2 \\
\hline & 309.0 & 272.0 & 252.0 \\
\hline
\end{tabular}

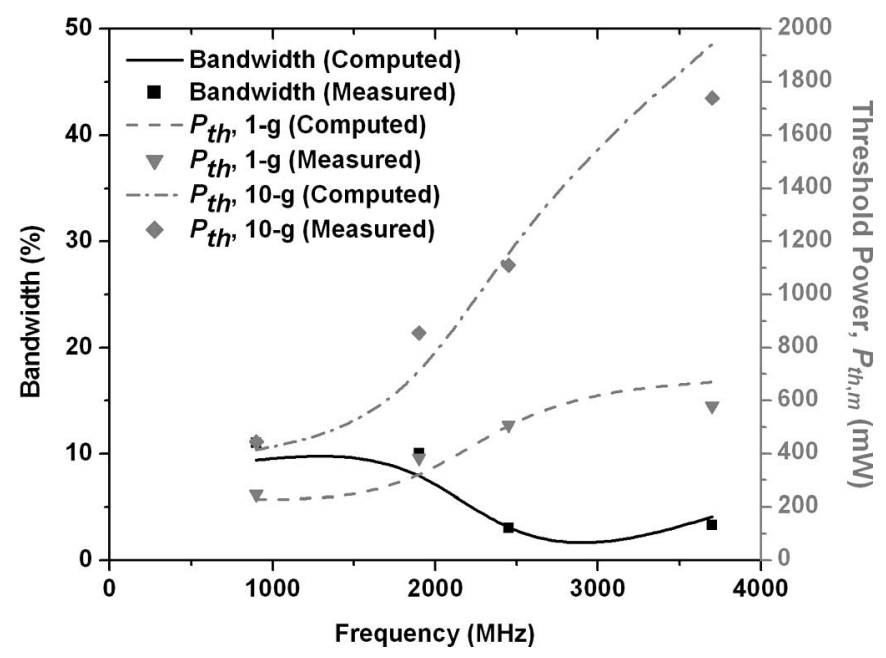

Fig. 7. Half-power bandwidth in free-space and threshold power of PIFAs at $h=20 \mathrm{~mm}$ for the conventional orientation.

TABLE II

COMPARISON OF SINGLE-BAND PlanAR ANTENNAS AT $f=2450 \mathrm{MHz}$ AND $h=13 \mathrm{~mm}$ (CONVENTIONAL ORIENTATION)

\begin{tabular}{lccc}
\hline \hline Antenna Type & PIFA & IFA & Patch \\
\hline BW (Computed), \% & 3.1 & 4.7 & 6.1 \\
\hline BW (Measured), \% & 3.1 & 5.2 & 5.7 \\
\hline Efficiency (Computed), \% & 27.9 & 23.1 & 52.3 \\
\hline$P_{t h, 1 g}$, (Computed), mW & 313.7 & 82.5 & 1454.5 \\
\hline$P_{t h, 1 g}$, (Measured), $\mathrm{mW}$ & 329.0 & 99.0 & 1168.0 \\
\hline$P_{t h, 10 g}$, (Computed), $\mathrm{mW}$ & 833.3 & 253.2 & 3703.7 \\
\hline$P_{t h, 10 g}$, (Measured), mW & 995.0 & 328.0 & 2632.4 \\
\hline \hline
\end{tabular}

also results in a more concentrated current distribution, resulting in a more focused SAR distribution and a lower value for $P_{\mathrm{th}, m}$ [22], [48]. Therefore, there is a positive correlation between BW and $P_{\mathrm{th}, m}$. Efficiency values for these antennas are similar. This is expected, as the radiating characteristics of these three antennas are similar, resulting in similar levels of absorbed power in the phantom (linear and meander dipole results exhibit the same behavior in [10]).

3) Planar Antennas: In Fig. 7, bandwidth and $P_{\mathrm{th}, m}$ of PIFAs are plotted versus frequency for $h=20 \mathrm{~mm}$. Simulated and measured data are in excellent agreement. The bandwidths of the antennas at 2450 and $3700 \mathrm{MHz}$ are narrower than the bandwidths at 900 and $1900 \mathrm{MHz}$ due to the existence of the FR4 substrate that reduces the antenna size. The threshold power 
TABLE III

COMPARISON OF Single-BAND PlanAR Antennas at $f=2450 \mathrm{MHz}$ AND $h=10 \mathrm{~mm}$ (FLIPPED ORIENTATION)

\begin{tabular}{lccc}
\hline \hline Antennas & PIFA & IFA & Patch \\
\hline Efficiency (Computed), $\%$ & 26.2 & 11.9 & 17.0 \\
\hline$P_{t h, 1 g},($ Computed), mW & 71.7 & 99.3 & 66.8 \\
\hline$P_{t h, 1 g}$, (Measured), $\mathrm{mW}$ & 69.0 & 160.5 & 66.0 \\
\hline$P_{t h, 10 g},($ Computed), $\mathrm{mW}$ & 245.4 & 303.5 & 152.7 \\
\hline$P_{t h, 10 \mathrm{~g}}$, (Measured), $\mathrm{mW}$ & 248.0 & 348.0 & 158.0 \\
\hline \hline
\end{tabular}

increases with frequency at $20 \mathrm{~mm}$ due to the larger electrical distance.

Tables II and III compare the computed and measured bandwidth, efficiency, and $P_{\mathrm{th}, m}$ of PIFA, IFA, and patch antennas for the conventional and flipped orientations. The patch antenna induces the lowest SAR (highest $P_{\mathrm{th}, m}$ ) in the conventional orientation and the highest SAR (lowest $P_{\mathrm{th}, m}$ ) in the flipped orientation. This is due to the antenna's high directivity $(\approx 6 \mathrm{dBi})$ relative to the other antennas, which in the conventional orientation confines the radiated power away from the phantom.

\section{B. Threshold Power Comparison}

A comparison of the threshold powers of the different antenna types studied is necessary to develop the threshold power formula. The results are compared in Fig. 8(a) for all antennas investigated at $f=2450 \mathrm{MHz}$ and $h=20 \mathrm{~mm}$. A similar comparison is presented in Fig. 8(b) for antennas at $f=900 \mathrm{MHz}$ and $h \approx 10 \mathrm{~mm}$. From Fig. 8, it is seen that the dipole antennas yield the lowest $P_{\mathrm{th}, m}$. This is also the case for the other frequencies and distances investigated, with three exceptions. The exceptions observed were for the patch antenna in the flipped orientation at the two highest frequencies and distances (i.e., at $f=3700 \mathrm{MHz}$ for $h=20 \mathrm{~mm}$ and at $6000 \mathrm{MHz}$ for $h=10$ and $20 \mathrm{~mm}$ ). This observation will be addressed in detail later. Based on the results of this study, the dipole antennas are selected to develop a formula for threshold power.

\section{ANALYSIS}

The aim of this paper is to derive a simple formula for $P_{\mathrm{th}, m}$ that is conservative and easy to implement. Since the dipole antennas induce the lowest threshold power compared to the other low-directivity antennas, dipole data were used to develop the formula. In order to make the formula practical for an engineer to use, the formula is a function of three antenna parameters that are easy to determine: the half-power bandwidth of the antenna in free space (BW), the center frequency within this bandwidth $(f)$, and the distance of the device to the user's head or body $(s)$. The threshold power is closely related to bandwidth, frequency, and distance, as described earlier.

In Fig. 1, $h$ was used to denote the distance from the antenna feedpoint to the phantom material. From a practical standpoint, it is often difficult to know where the antenna feedpoint is on a portable wireless device (or even where the antenna is located). To make the formula easier for an engineer to use, we use a new variable $s$ to denote the closest distance between the nearest surface of the portable wireless device and the phantom. The relationship between $h$ and $s$ is

$$
s=h-\Delta
$$

where $\Delta$ is the distance between the antenna's feedpoint and the closest point on the portable wireless device to the phantom. This means that $s$ is always less than or equal to $h$. For instance, for the $900 \mathrm{MHz}$ PIFA in the conventional orientation, the box width is $\Delta=10 \mathrm{~mm}$, so $s=3 \mathrm{~mm}$ when $h=13 \mathrm{~mm}$. Using $s$ rather than $h$ in the formula also makes the formula more conservative. This is because the dipole antennas are located at a distance of $s=h$ from the phantom, while $s<h$ for most practical devices. Therefore, the device is being evaluated as if the feedpoint was at the closest surface of the device to the phantom. The smaller distance leads to a lower (more conservative) value for $P_{\text {th, } m}$.

For the analysis, dipole antenna simulations at a distance of $s$ $=25 \mathrm{~mm}$ were added to the existing data at $s=h=5,10$, and $20 \mathrm{~mm}$. The relationships between the computed $P_{\mathrm{th}, 10 \mathrm{~g}}$ and the parameters $s, f$, and $B W$ are illustrated in Fig. 9(a)-(c), respectively. A semi-log plot of $P_{\mathrm{th}, 10 \mathrm{~g}}$ versus $s$ in Fig. 9(a) indicates that there is a nearly linear relationship between $\ln \left(P_{\mathrm{th}, 10 \mathrm{~g}}\right)$ and $s$. In fact, a second-order polynomial in $s$ provides a good fit to $\ln \left(P_{\mathrm{th}, 10 \mathrm{~g}}\right)$. Similarly a semi-log plot of $P_{\mathrm{th}, 10 \mathrm{~g}}$ versus $f$ in Fig. 9(b) shows that $\ln \left(P_{\mathrm{th}, 10 \mathrm{~g}}\right)$ can be described by a third-order polynomial in $f$. Finally, a log-log plot of $P_{\mathrm{th}, 10 \mathrm{~g}}$ versus $B W$ in Fig. 9(c) indicates a linear relationship between $\ln \left(P_{\mathrm{th}, 10 \mathrm{~g}}\right)$ and $\ln (B W)$. The same observations can also be drawn from the $P_{\mathrm{th}, 1 \mathrm{~g}}$ data. These observations led to the following formula to estimate the threshold power for a wireless device near the head or body of a user

$$
P_{\max , m}=\exp \left(A s+B s^{2}+C \ln (B W)+D\right)
$$

where $P_{\max , m}$ is a best-fit underestimate of the $P_{\mathrm{th}, m}$ data obtained from FDTD computations. In (3), $s$ is expressed in millimeters and $B W$ in percent (e.g., enter " 10 " if bandwidth is $10 \%)$. $A, B, C$, and $D$ are third-order polynomials of frequency.

A least-squares fit of (3) to the computed dipole antenna data was initially used to solve for $A, B, C$, and $D$. Different variations of the formula were investigated (e.g., adding an $s^{2}$ component, changing the polynomial order of the frequency dependence) to improve the fit while keeping the formula simple. Subsequently, some of the parameters in the $A, B, C$, and $D$ polynomials were manually adjusted to ensure that $P_{\max , m} \leq P_{\mathrm{th}, m}$ for all dipole data points. This led to the following solution for $\mathrm{SAR}_{\text {limit, } 1 \mathrm{~g}}=$ $1.6 \mathrm{~W} / \mathrm{kg}$ :

$$
\begin{aligned}
& A=\left(-0.4922 f^{3}+4.831 f^{2}-6.620 f+8.312\right) / 100 \\
& B=\left(0.1191 f^{3}-1.470 f^{2}+3.656 f-1.697\right) / 1000 \\
& C=\left(-0.4228 f^{3}+13.24 f^{2}-108.1 f+339.4\right) / 1000 \\
& D=-0.02440 f^{3}+0.4075 f^{2}-2.330 f+4.730 .
\end{aligned}
$$

For $\mathrm{SAR}_{\text {limit, } 10 \mathrm{~g}}=2 \mathrm{~W} / \mathrm{kg}$, the following solution was obtained:

$$
\begin{aligned}
& A=\left(-0.4588 f^{3}+4.407 f^{2}-6.112 f+2.497\right) / 100 \\
& B=\left(0.1160 f^{3}-1.402 f^{2}+3.504 f-0.4367\right) / 1000
\end{aligned}
$$




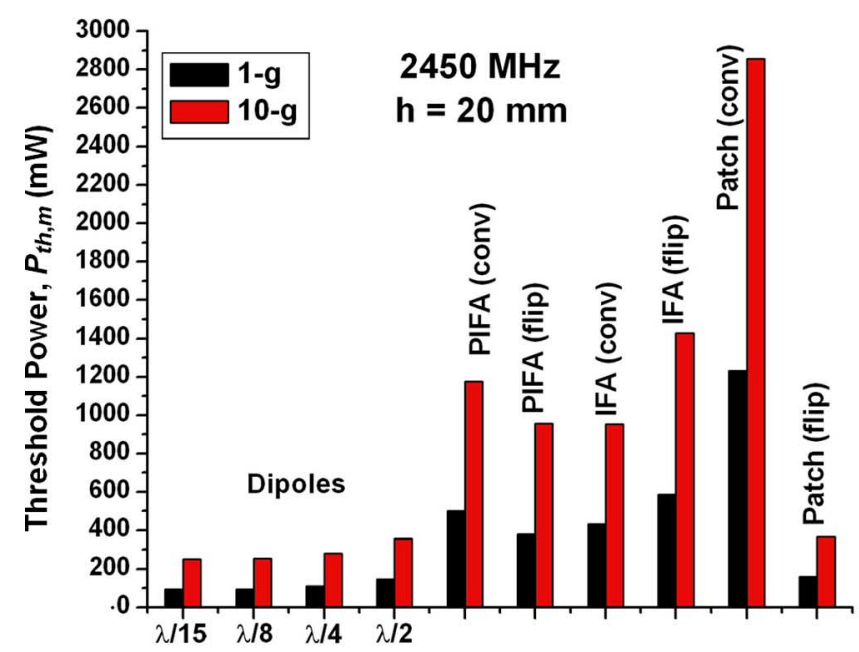

(a)

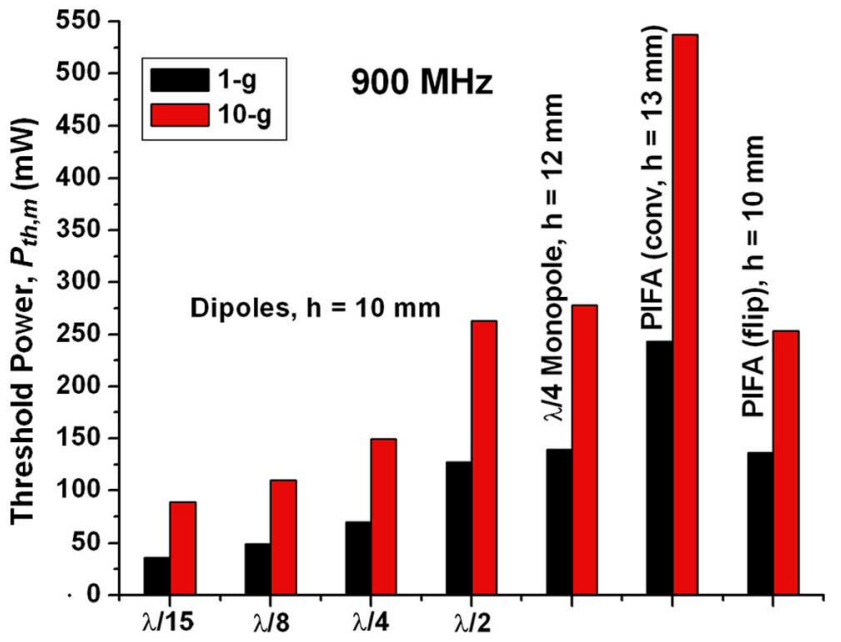

(b)

Fig. 8. Bar charts of threshold power $P_{\mathrm{th}, m}$ for (a) all antennas investigated at $f=2450 \mathrm{MHz}$ and $h=20 \mathrm{~mm}$, and (b) all antennas investigated at $900 \mathrm{MHz}$ and $h \approx 10 \mathrm{~mm}$ (exact distances are as indicated).

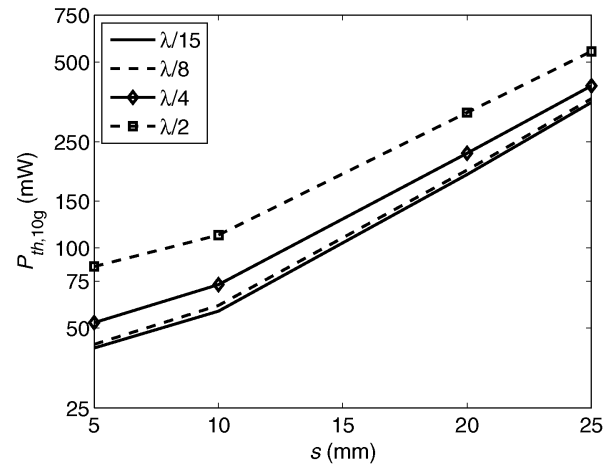

(a)

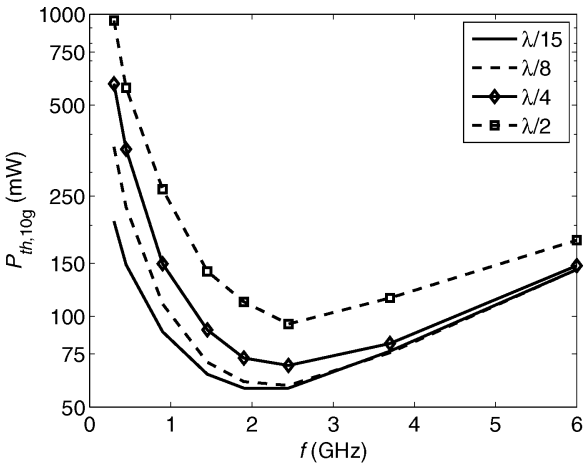

(b)

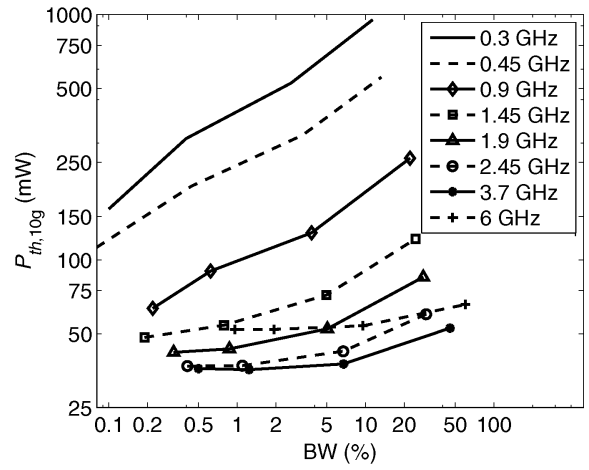

(c)

Fig. 9. Threshold power levels for $\mathrm{SAR}_{\text {limit }, 10 \mathrm{~g}}=2 \mathrm{~W} / \mathrm{kg}$ for four linear dipole antennas as a function of (a) distance $s$ at $f=1.9 \mathrm{GHz}$, (b) frequency $f$ at $s=10 \mathrm{~mm}$, and (c) bandwidth $B W$ at $s=5 \mathrm{~mm}$. The electrical lengths of the four dipole antennas are shown in the legend of (a) and (b), and the frequencies are shown in the legend of (c).

$$
\begin{aligned}
& C=\left(-0.1333 f^{3}+11.89 f^{2}-110.8 f+301.4\right) / 1000 \\
& D=-0.03540 f^{3}+0.5023 f^{2}-2.297 f+6.104
\end{aligned}
$$

In (4) and (5), $f$ is expressed in gigahertz. The formula in (3)(5) can also be linearly scaled to other SAR limits having the same averaging mass. For example, the International Commission on Non-Ionizing Radiation Protection (ICNIRP) specifies $\mathrm{SAR}_{\text {limit }, 10 \mathrm{~g}}=4 \mathrm{~W} / \mathrm{kg}$ for the general population exposure of the limbs and $\mathrm{SAR}_{\text {limit, } 10 \mathrm{~g}}=20 \mathrm{~W} / \mathrm{kg}$ for occupational exposure of the head and trunk. In these two cases, $\mathrm{P}_{\max , m}$ would be determined by first solving (3) and (5), then multiplying the result by factors of $4 / 2=2$ and $20 / 2=10$, respectively. Similarly, if $\mathrm{SAR}_{\text {limit, } 1 \mathrm{~g}}=8 \mathrm{~W} / \mathrm{kg}$ from [5] is applicable, the result of (3) and (4) would be multiplied by a factor of $8 / 1.6=5$ to determine $P_{\max , m}$.

\section{COMPARISON}

Values of $P_{\max , 1 \mathrm{~g}}$ and $P_{\max , 10 \mathrm{~g}}$ estimated using (3)-(5) are plotted versus frequency in Fig. 10(a) and (b) for four different cases of $s$ and $B W$. The four distances, $s$, represent the valid range of distances in this paper, from $s=2 \mathrm{~mm}$ (i.e., the closest distance where the device is touching the 2 -mm-thick phantom shell) to $s=25 \mathrm{~mm}$. The four bandwidths, $B W$ are selected from among the typical bandwidths of portable wireless devices listed in Table IV, plus a very narrow bandwidth of $1 \%$. It can be seen that the values of $P_{\max , 1 \mathrm{~g}}$ and $P_{\max , 10 \mathrm{~g}}$ are always above the physical limits of $1.6 \mathrm{~mW}$ and $20 \mathrm{~mW}$, respectively, even in the extreme case when $s=2 \mathrm{~mm}$ and $B W=1 \%$.

Table IV shows $P_{\max , m}$ values for typical operating frequency bands used by portable wireless devices calculated from (3)-(5) at $s=5 \mathrm{~mm}$ and $25 \mathrm{~mm}$. For this exercise, bandwidth was set to the frequency band of the communication system. The values in Table IV may be used to get an impression of what threshold power levels could be expected in these frequency bands. For example, a GSM mobile telephone typically transmits at $125 \mathrm{~mW}$ output power in a bandwidth centered at $1795 \mathrm{MHz}$. Table IV row 13 shows that if bandwidth for a GSM mobile telephone handset covers at least the $9.5 \%$ bandwidth of the communication system, it cannot be exempted from SAR testing if it is located $s=5 \mathrm{~mm}$ away from the body, but it could be exempted at $25 \mathrm{~mm}$ 


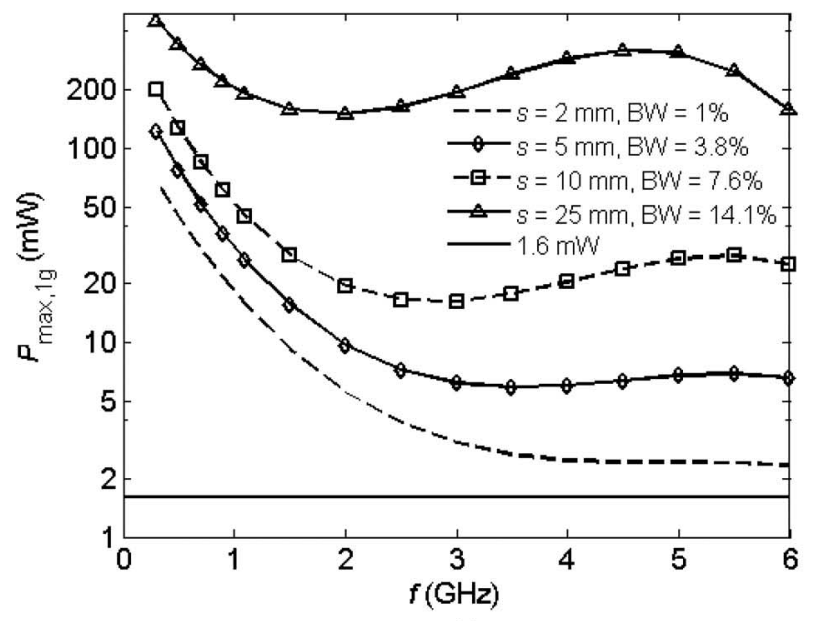

(a)

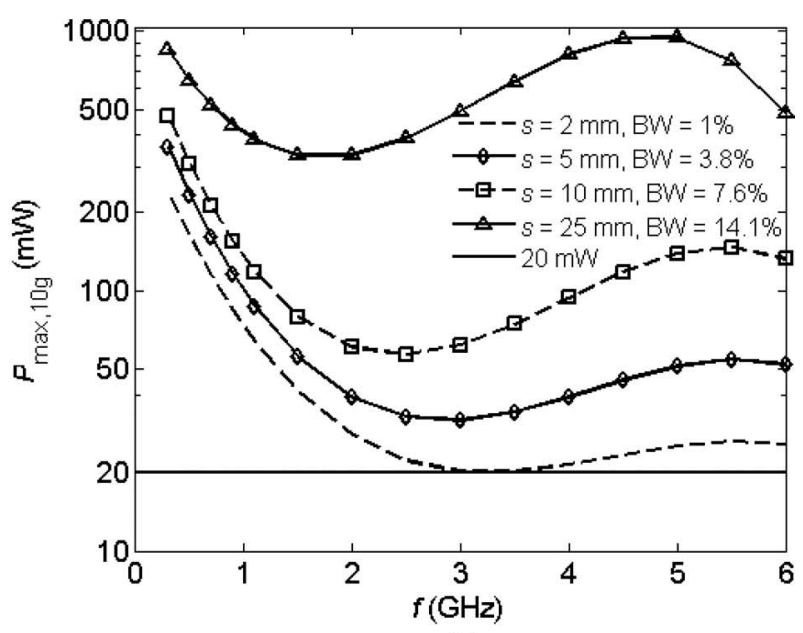

(b)

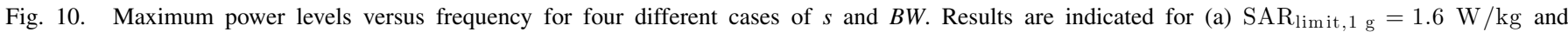
(b) $\mathrm{SAR}_{\text {limit, } 10 \mathrm{~g}}=2 \mathrm{~W} / \mathrm{kg}$. The levels are compared with the trivial threshold power levels of (a) $1.6 \mathrm{~mW}$ and (b) $20 \mathrm{~mW}$.

TABLE IV

SOME TYPICAL FREQUENCY BANDS OF PORTABLE WIRELESS DEVICES AND Their Threshold POWER PREDicted Using (3)-(5)

\begin{tabular}{|c|c|c|c|c|c|c|}
\hline \multirow{2}{*}{$\begin{array}{c}f \\
(\mathrm{GHz})\end{array}$} & \multirow{2}{*}{$\begin{array}{l}B W \\
(\%)\end{array}$} & \multirow{2}{*}{$\begin{array}{c}\text { Example } \\
\text { air } \\
\text { interface }\end{array}$} & \multicolumn{2}{|c|}{$s=5 \mathrm{~mm}$} & \multicolumn{2}{|c|}{$s=25 \mathrm{~mm}$} \\
\hline & & & $\begin{array}{l}P_{\max , 1 \mathrm{~g}} \\
(\mathrm{~mW})\end{array}$ & $\begin{array}{c}P_{\max , 10 \mathrm{~g}} \\
(\mathrm{~mW})\end{array}$ & $\begin{array}{l}P_{\max , 1 \mathrm{~g}} \\
(\mathrm{~mW})\end{array}$ & $\begin{array}{l}P_{\max , 10 \mathrm{~g}} \\
(\mathrm{~mW})\end{array}$ \\
\hline 0.393 & 3.8 & TETRA & 97 & 292 & 265 & 526 \\
\hline 0.420 & 4.8 & TETRA & 98 & 293 & 274 & 541 \\
\hline 0.461 & 3.3 & GSM & 80 & 244 & 233 & 468 \\
\hline 0.485 & 14.4 & $\mathrm{APCO}$ & 117 & 337 & 347 & 660 \\
\hline 0.838 & 7.6 & iDEN & 48 & 148 & 198 & 399 \\
\hline 0.859 & 8.1 & IS-136 & 47 & 145 & 198 & 398 \\
\hline 0.884 & 16.7 & PDC & 54 & 162 & 233 & 456 \\
\hline 0.896 & 5.7 & TETRA & 40 & 127 & 176 & 360 \\
\hline 0.918 & 4.8 & iDEN & 37 & 118 & 165 & 342 \\
\hline 0.925 & 7.6 & GSM & 41 & 129 & 185 & 375 \\
\hline 1.465 & 4.9 & PDC & 17 & 60 & 128 & 281 \\
\hline 1.795 & 9.5 & GSM & 13 & 50 & 139 & 308 \\
\hline 1.920 & 7.3 & GSM & 11 & 44 & 132 & 302 \\
\hline 2.045 & 12.2 & UMTS & 11 & 44 & 146 & 330 \\
\hline 2.350 & 4.3 & WiBro & 7.9 & 34 & 130 & 323 \\
\hline 2.442 & 3.4 & Bluetooth & 7.3 & 32 & 130 & 328 \\
\hline 3.550 & 14.1 & WiMAX & 6.7 & 37 & 244 & 657 \\
\hline 5.250 & 3.8 & WiMAX & 6.8 & 53 & 258 & 845 \\
\hline 5.788 & 1.3 & WiMAX & 6.2 & 52 & 164 & 564 \\
\hline
\end{tabular}

distance from the body (e.g., while held in a 25 -mm-thick carry accessory). Table IV is only a guide. The reader should always use the correct values of $s, B W$, and $f$ that apply to the specific portable wireless device under investigation. The value of $B W$ should be the measured $\left|S_{11}\right| \leq-7 \mathrm{~dB}$ bandwidth of the antenna in free space. The value of $f$ is the center frequency of the bandwidth $B W$. The value of $s$ is from the manufacturer's intended use of the device, which indicates how the device would be tested for SAR compliance (e.g., worn on the body in a belt clip that is $15 \mathrm{~mm}$ thick). There may be more than one intended use of a product, resulting in more than one value of $s$. In this case, the formula can be evaluated separately for each intended use. This information is known by the engineer prior to SAR compliance testing.

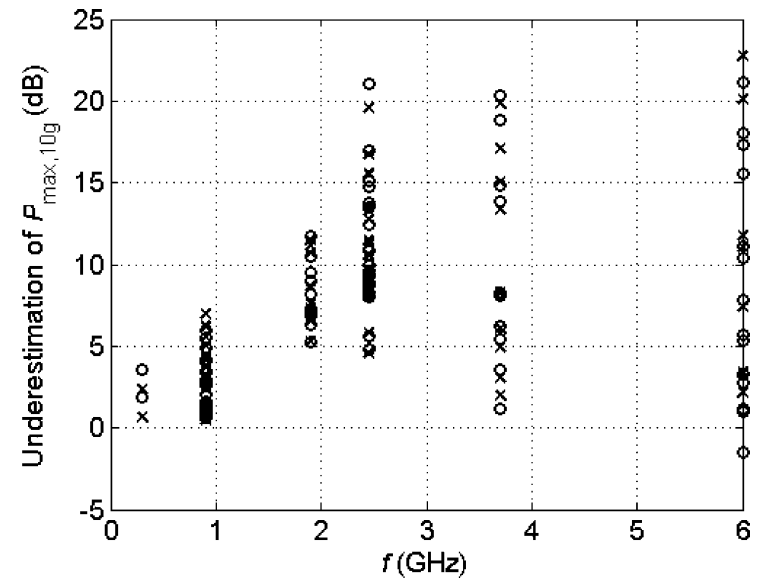

Fig. 11. Comparison of $P_{\max , 10 \mathrm{~g}}$ of (3)-(5) against the measured (x) and simulated (o) threshold powers of antenna models used in this study. The amount of underestimation of the formula is shown for all models, as a function of frequency.

\section{A. Comparison Between Estimated $P_{\max , \mathrm{m}}$ and Simulated and Measured $P_{\mathrm{th}, m}$}

In Fig. 11, a comparison is made between $P_{\max , 10 \mathrm{~g}}$ and the threshold power levels, $P_{\mathrm{th}, 10 \mathrm{~g}}$, for all the antennas studied in this paper. The underestimation of $P_{\max , 10 \mathrm{~g}}$ is plotted in decibels on the vertical axis. The underestimation is equal to $10 \log _{10}\left(P_{\mathrm{th}, 10 \mathrm{~g}} / P_{\max , 10 \mathrm{~g}}\right)$. Results are presented for both the measured and simulated data. All antennas were made to be perfectly matched at the center frequency, and simulated antennas have no conductor losses. Therefore, these antennas will have lower $P_{\mathrm{th}, m}$ values (thereby giving lower underestimation values) than they would have had in practice.

It is seen that for all the antennas except one, the underestimation is positive, i.e., $P_{\max , 10 \mathrm{~g}}<P_{\mathrm{th}, 10 \mathrm{~g}}$ (the same is true for $\left.P_{\max , 1 \mathrm{~g}}\right)$. For these cases, the underestimation ranges from 0.5 to $23 \mathrm{~dB}$ with an average underestimation of $12 \mathrm{~dB}$ (for $P_{\max , 1 \mathrm{~g}}$, the underestimation ranges from 1.1 to $27 \mathrm{~dB}$ with an 


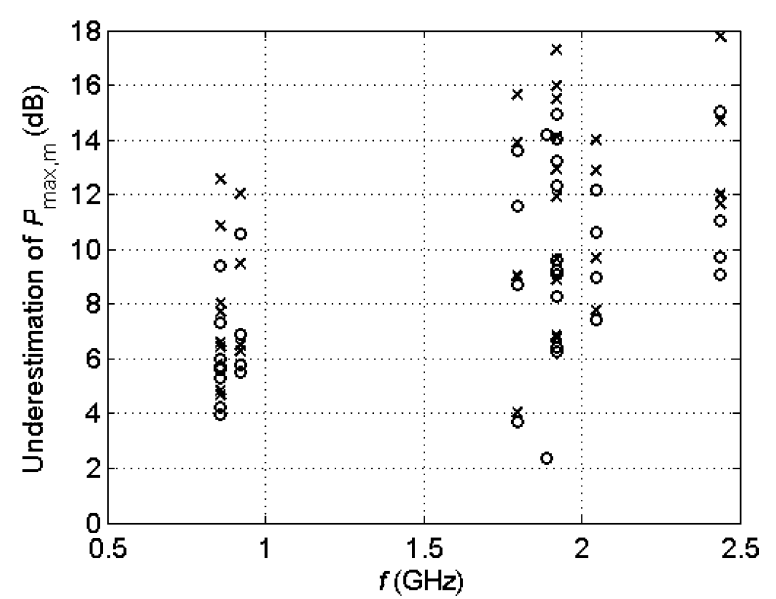

Fig. 12. Comparison of $P_{\max , m}$ of (3)-(5) against the measured threshold powers of commercially available mobile telephone models collected for this study. The underestimation of $P_{\mathrm{max}, m}$ is shown as a function of frequency for $m=1 \mathrm{~g}(\mathrm{x})$, and $m=10 \mathrm{~g}(\mathrm{o})$.

average of $14 \mathrm{~dB}$ ). This indicates that using the dipole data to determine $P_{\max , m}$ was a good choice. It is also seen that the lowest values of the $P_{\max , 10 \mathrm{~g}}$ underestimation are consistent across the range of frequencies, meaning that $P_{\max }, 10 \mathrm{~g}$ is not significantly biased toward low or high frequencies (the same was observed over the range of values of $s$ and $B W$ ). There is one antenna for which $P_{\mathrm{max}, m}$ does not underestimate $P_{\mathrm{th}, m}$. This issue will be addressed in further detail within Section VI.

\section{B. Comparison Between Estimated $P_{\max , m}$ and Practical Device Data}

SAR and transmit power data of several commercially available mobile telephone models were collected from the manufacturers and analyzed. The power corresponds to the maximum conducted power at the antenna port measured into a $50 \Omega$ load. Data were collected for models used at the head and worn on the body. For models used at the head, a distance of $s=5 \mathrm{~mm}$ was assumed. For models used at the body, the distance supplied by the manufacturer was used. The manufacturers also supplied the frequency information, including the operating bandwidth of the device (it was assumed that the operating bandwidth is equal to the $-7 \mathrm{~dB}$ bandwidth, as done for Table IV). The threshold powers for these models were calculated and are compared against $P_{\max , m}$ in Fig. 12. Clearly $P_{\max , m}$ significantly underestimates the threshold power levels for all of these mobile phones. The underestimation is always over $2 \mathrm{~dB}$, and in some cases, over $10 \mathrm{~dB}$ for the models studied.

Kivekäs et al. explored the relationship between bandwidth and SAR for two planar antennas at 900 and $1800 \mathrm{MHz}$ [26]. Data are available in their paper for $s, B W, f$, and SAR of the two antennas. The paper provides the $-6 \mathrm{~dB}$ bandwidth, which is wider than the $-7 \mathrm{~dB}$ bandwidth. A comparison of the formula with their data reveals that the formula underestimates the threshold powers by 3.6 to $8 \mathrm{~dB}$. Had they provided the $-7 \mathrm{~dB}$ bandwidth for the antennas, the underestimation would have been even greater. These results are in line with the mobile phone data in Fig. 12.
TABLE V

Dipole AND Microstrip PATCH $P_{\mathrm{th}, 10 \mathrm{~g}}$ COMPARISON

\begin{tabular}{ccccc}
\hline \hline & \multicolumn{4}{c}{$P_{t h, 10 \mathrm{~g}}(\mathrm{~mW})$} \\
\cline { 2 - 5 } Antenna & $(\mathrm{mm})$ & $2.45 \mathrm{GHz}$ & $3.7 \mathrm{GHz}$ & $6 \mathrm{GHz}$ \\
\hline Patch & 10 & 152 & 116 & $\mathbf{1 0 4}$ \\
\cline { 2 - 5 } (flipped orientation) & 20 & 366 & $\mathbf{3 0 3}$ & $\mathbf{2 2 5}$ \\
\hline \multirow{2}{*}{$\lambda / 15$ dipole } & 10 & 58 & 77 & 143 \\
\cline { 2 - 5 } & 20 & 250 & 392 & 455 \\
\hline \multirow{2}{*}{$\lambda / 2$ dipole } & 10 & 94 & 115 & 179 \\
\cline { 2 - 5 } & 20 & 357 & 488 & 488 \\
\hline \hline
\end{tabular}

Bold emphasis indicates that $\mathrm{P}_{\text {th, } 10 \mathrm{~g}}$ for the patch antenna is below that of the dipole antennas.

\section{DISCUSSION}

The $P_{\max , m}$ value predicted by the formula proposed in this paper underestimates all antennas investigated in this study but one. This highlights an important point: the threshold power derived in this paper is expected to be conservative for typical antennas for portable wireless devices, but it is not conservative for all antenna types. The exception among all antennas investigated is a microstrip patch antenna operating at $6 \mathrm{GHz}$ and facing toward the phantom (i.e., in the flipped orientation) at a distance of $h=20 \mathrm{~mm}$. In this instance, the simulated threshold powers, $P_{\mathrm{th}, m}$, of the dipole antennas are greater than $P_{\mathrm{th}, m}$ of this patch antenna. There are two other instances of patch antennas where this is also the case (as explained in Section III-B). The reason why the formula overestimates in only one instance is because of conservative factors introduced in the formula, including the use of $s$ instead of $h$ for distance and adjustments applied to the formula to ensure that $P_{\max , m} \leq P_{\mathrm{th}, m}$ for all dipole data points.

It was observed that when microstrip patch antennas are oriented toward the phantom at larger electrical distances $s / \lambda$, they result in lower values of $P_{\mathrm{th}, m}$ than the shortest dipoles. For instance, at $6 \mathrm{GHz}$, the patch placed at $h=10$ and $20 \mathrm{~mm}(s=$ 7 and $17 \mathrm{~mm}$ due to the $3-\mathrm{mm}$ patch height) from the phantom gives $P_{\mathrm{th}, 10 \mathrm{~g}}$ values of 104 and $225 \mathrm{~mW}$ while a $\lambda / 15$ dipole gives 143 and $455 \mathrm{~mW}$ (see Table V). A similar situation is repeated at $3.7 \mathrm{GHz}$ but only for the $20 \mathrm{~mm}$ distance, while at $2.45 \mathrm{GHz}$, this situation is not evident at either distance. The same conclusions are true of $P_{\mathrm{th}, 1 \mathrm{~g}}$. This is clearly a different phenomenon that involves directive antennas at large electrical distances. For $h=20 \mathrm{~mm}$ and at $6 \mathrm{GHz}$, the SAR induced by a directive patch radiating toward the phantom is 2.24 times that of a half-wave dipole. Interestingly, the directivity of the patch antenna in this case is 2.6 times the directivity of a half-wave dipole. So, the difference in $P_{\mathrm{th}, m}$ is related to the directive nature of the patch.

It is seen in Fig. 9(b) that the threshold power levels of the four dipoles are converging at the higher frequencies. Seen another way, in Fig. 9(c), the dependence of the threshold power on bandwidth is decreasing at the higher frequencies, such that the threshold power curve is nearly flat at $6 \mathrm{GHz}$. As the frequency and physical distance to the phantom increase, the electrical distance to the phantom increases to the point where the phantom may no longer be in the reactive near-field region of the antenna. The threshold power should be more dependent on directivity than bandwidth in this region. Thus, in this region, directivity 
will be a critical parameter in order to develop threshold power rationale.

Typical microstrip patch antennas on foam with a $\lambda / 2$ aperture size provide directivity in excess of $6 \mathrm{dBi}$ while $\lambda / 2$ and infinitesimal dipoles have directivities of 2.2 and $1.8 \mathrm{dBi}$, respectively [34]. The dipole antennas therefore have similar directivities and similar $P_{\mathrm{th}, m}$ values when operating at large electrical distances from the phantom. However, the situation is completely different when the dipole antennas are electrically very close to the phantom. At the lower frequencies, the $P_{\mathrm{th}, m}$ values are very different and not explained by the directivity [see Fig. 9(b) and (c)].

These observations lead to the conclusion that when the phantom is in the near-field region of the antenna, the antenna bandwidth should be used to predict $P_{\mathrm{th}, m}$. For far-field cases, $P_{\mathrm{th}, m}$ can be better predicted from the antenna directivity. In some cases, the relationship may contain both bandwidth and directivity, for instance, when the phantom is in the radiating near-field. This will be the subject of a future research study.

\section{CONCLUSION}

A methodical investigation of a number of antenna types, sizes, and shapes was conducted to understand the relationship between antenna parameters (frequency, distance to the body, and antenna free-space bandwidth) and the SAR so as to determine the threshold power. The study included frequencies ranging from 300 to $6000 \mathrm{MHz}$, which includes a variety of mobile telephone applications. It was observed that for the classes, shapes, and sizes of antennas investigated, the wire dipole antenna generally allowed the lowest (i.e., most conservative) value for threshold power. By correlating the bandwidth, center frequency, and distance to the body of dipole antennas with the threshold power, a new formula was developed to estimate the threshold power of a wireless device. The conservative nature of the formula has been demonstrated by comparing the estimated threshold powers given by the formula with those obtained from direct simulations and measurements.

\section{REFERENCES}

[1] C. K. Chou, H. Bassen, J. Osepchuk, Q. Balzano, R. Petersen, M. Meltz, R. Cleveland, J. C. Lin, and L. Heynick, "Radio frequency electromagnetic exposure: Tutorial review on experimental dosimetry," Bioelectromagnetics, vol. 17, no. 3, pp. 195-208, 1996.

[2] Q. Balzano, O. Garay, and T. J. Manning, "Electromagnetic energy exposure of simulated users of portable cellular telephones," IEEE Trans. Veh. Technol., vol. 44, no. 3, pp. 390-403, Aug. 1995.

[3] T. Schmid, O. Egger, and N. Kuster, "Automated E-field scanning system for dosimetric assessments," IEEE Trans. Microw. Theory Tech., vol. 44, no. 1, pp. 105-113, Jan. 1996.

[4] K. S. Yee, "Numerical solution of initial boundary value problems involving Maxwell's equations in isotropic media," IEEE Trans. Antennas Propag., vol. AP-14, no. 3, pp. 302-307, May 1966.

[5] IEEE Standard for Safety Levels with Respect to Human Exposure to Radio Frequency Electromagnetic Fields, $3 \mathrm{kHz}$ to $300 \mathrm{GHz}$, IEEE Standard C95.1-1991.

[6] ICNIRP, "International Commission on Non-Ionizing Radiation Protection. Guidelines for limiting exposure to time-varying electric, magnetic and electromagnetic fields (up to $300 \mathrm{GHz}$ )," Health Phys., vol. 74, no. 4, pp. 494-522, 1998.
[7] IEEE Standard for Safety Levels with Respect to Human Exposure to Radio Frequency Electromagnetic Fields, $3 \mathrm{kHz}$ to $300 \mathrm{GHz}$, IEEE Standard C95.1-2005.

[8] Generic Standard to Demonstrate the Compliance of Low Power Electronic and Electrical Apparatus With the Basic Restrictions Related to Human Exposure to Electromagnetic Fields $(10 \mathrm{MHz}-300 \mathrm{GHz})$-General Public, Draft IEC Standard 62479, Sep. 2008.

[9] Generic Standard to Demonstrate the Compliance of Low Power Electronic and Electrical Apparatus With the Basic Restrictions Related to Human Exposure to Electromagnetic Fields (10 MHz-300 GHz)—General Public, CENELEC Standard EN 50371, Nov. 2002.

[10] M. Ali, M. G. Douglas, A. T. M. Sayem, A. Faraone, and C.-K. Chou, "Threshold power of canonical antennas for inducing SAR at compliance limits in the 300-3000 MHz frequency range," IEEE Trans. Electromagn. Compat., vol. 49, no. 1, pp. 143-152, Feb. 2007.

[11] N. Kuster and Q. Balzano, "Energy absorption mechanism by biological bodies in the near field of dipole antennas," IEEE Trans. Veh. Technol., vol. 41, no. 1, pp. 17-23, Feb. 1992.

[12] M. A. Jensen and Y. Rahmat-Samii, "EM Interaction of handset antennas and a human in personal communications," Proc. IEEE, vol. 83, no. 1, pp. 7-17, Jan. 1995.

[13] M. Okoniewski and M. A. Stuchly, "A study of the handset antenna and human body interaction," IEEE Trans. Microw. Theory Tech., vol. 44, no. 10, pp. 1855-1864, Oct. 1996.

[14] V. Hombach, K. Meier, M. Burkhardt, E. Kühn, and N. Kuster, "The dependence of EM energy absorption upon human head modeling at $900 \mathrm{MHz}$," IEEE Trans. Microw. Theory Tech., vol. 44, no. 10, pp. 1865-1873, Oct 1996.

[15] K. Meier, V. Hombach, R. Kästle, R.Y.-S. Tay, and N. Kuster, "The dependence of electromagnetic energy absorption upon human-head modeling at $1800 \mathrm{MHz}$," IEEE Trans. Microw. Theory Tech., vol. 45, no. 11, pp. 2058-2062, Nov. 1997.

[16] S. Watanabe, M. Taki, T. Nojima, and O. Fujiwara, "Characteristics of the SAR distributions in a head exposed to electromagnetic fields radiated by a hand-held portable radio," IEEE Trans. Microw. Theory Tech., vol. 44, no. 10 , pp. $1874-1883$, Oct. 1996.

[17] O. P. Gandhi, G. Lazzi, and C. Furse, "Electromagnetic absorption in the human head and neck for mobile telephones at 835 and $1900 \mathrm{MHz}$," IEEE Trans. Microw. Theory Tech., vol. 44, no. 10, pp. 1884-1897, Oct. 1996.

[18] Q. Balzano, M. Y. Kanda, and C. C. Davis, "Specific absorption rates in a flat phantom in the near-field of dipole antennas," IEEE Trans. Electromagn. Compat., vol. 48, no. 3, pp. 563-568, Aug. 2006.

[19] C. C. Davis, B. B. Beard, A. Tillman, J. Rzasa, E. Merideth, and Q. Balzano, "International intercomparison of specific absorption rates in a flat absorbing phantom in the near-field of dipole antennas," IEEE Trans. Electromagn. Compat., vol. 48, no. 3, pp. 579-588, Aug. 2006.

[20] G. Lazzi and O. P. Gandhi, "On modeling and personal dosimetry of cellular telephone helical antennas with the FDTD code," IEEE Trans. Antennas Propag., vol. 46, no. 4, pp. 525-530, Apr. 1998.

[21] P. Bernardi, M. Cavagnaro, S. Pisa, and E. Piuzzi, "Power absorption and temperature elevations induced in the human head by a dual-band monopole-helix antenna phone," IEEE Trans. Microw. Theory Tech., vol. 49, no. 12, pp. 2539-2546, Dec. 2001.

[22] J. T. Rowley, R. B. Waterhouse, and K. H. Joyner, "Modeling of normalmode helical antennas at $900 \mathrm{MHz}$ and $1.8 \mathrm{GHz}$ for mobile communications handsets using the FDTD technique," IEEE Trans. Antennas Propag., vol. 50, no. 6, pp. 812-820, Jun. 2002.

[23] S. Koulouridis and K. S. Nikita, "Study of the coupling between human head and cellular phone helical antennas," IEEE Trans. Electromagn. Compat., vol. 46, no. 1, pp. 62-70, Feb. 2004.

[24] M. G. Douglas, M. Okoniewski, and M. A. Stuchly, "A planar diversity antenna for handheld PCS devices," IEEE Trans. Veh. Technol., vol. 47, no. 3, pp. 17-23, Aug. 1998.

[25] J. T. Rowley and R. B. Waterhouse, "Performance of shorted microstrip patch antennas for mobile communications handsets at $1800 \mathrm{MHz}$," IEEE Trans. Antennas Propag., vol. 47, no. 5, pp. 815-822, May 1999.

[26] O. Kivekäs, J. Ollikainen, T. Lehtiniemi, and P. Vainikainen, "Bandwidth SAR, and efficiency of internal mobile phone antennas," IEEE Trans. Electromagn. Compat., vol. 46, no. 1, pp. 71-86, Feb. 2004.

[27] K. C. Chim, K. C. L. Chan, and R. D. Murch, "Investigating the impact of smart antennas on SAR," IEEE Trans. Antennas Propag., vol. 52, no. 5 , pp. 1370-1374, May 2004.

[28] S. Kuhn, U. Lott, A. Kramer, and N. Kuster, "Assessment methods for demonstrating compliance with safety limits of wireless devices used in 
home and office environments," IEEE Trans. Electromagn. Compat., vol. 49, no. 3, pp. 519-525, Aug. 2007.

[29] C. M. Furse and O. P. Gandhi, "A memory efficient method of calculating specific absorption rate in CW FDTD simulations," IEEE Trans. Biomed. Eng., vol. 43, no. 5, pp. 558-560, May 1996.

[30] M. F. Iskander, H. Massoudi, C. H. Durney, and S. J. Allen, "Measurements of the RF power absorption in spheroidal human and animal phantoms exposed to the near field of a dipole source," IEEE Trans. Biomed. Eng., vol. BME-28, no. 3, pp. 258-264, Mar. 1981.

[31] M. Kanda, Q. Balzano, P. Russo, A. Faraone, and G. Bit-Babik, "Effects of ear-connection modeling on the electromagnetic-energy absorption in a human-head phantom exposed to a dipole antenna field at $835 \mathrm{MHz}$," IEEE Trans. Electromagn. Compat., vol. 44, no. 1, pp. 4-10, Feb. 2002.

[32] W. Kainz, A. Christ, T. Kellom, S. Seidman, N. Nikoloski, B. Beard, and N. Kuster, "Dosimetric comparison of the specific anthropomorphic mannequin (SAM) to 14 anatomical head models using a novel definition for the mobile phone positioning," Phys. Med. Biol., vol. 50, pp. 34233445, Jul. 2005.

[33] B. Beard, W. Kainz, T. Onishi, T. Iyama, S. Watanabe, O. Fujiwara, J. Wang, G. Bit-Babik, A. Faraone, J. Wiart, A. Christ, N. Kuster, A-K. Lee, H. Kroeze, M. Siegbahn, J. Keshvari, H. Abrishamkar, W. Simon, D. Manteuffel, and N. Nikoloski, "Comparisons of computed mobile phone induced SAR in the SAM phantom to that in anatomically correct models of the human head," IEEE Trans. Electromagn. Compat., vol. 48, no. 2, pp. 397-407, May 2006.

[34] C. A. Balanis, Antenna Theory: Analysis and Design, 3rd ed. New York: Wiley, 2005.

[35] J. S. McLean, "A re-examination of the fundamental limits on the radiation Q of electrically small antennas," IEEE Trans. Antennas Propag., vol. 44, no. 5, pp. 672-676, May 1996.

[36] IEEE Recommended Practice for Determining the Peak Spatial-Average Specific Absorption Rate (SAR) in the Human Head from Wireless Communication Devices: Measurement Techniques. IEEE Standard 1528-2003, Dec. 2003.

[37] Human Exposure to Radio Frequency Fields From Handheld and BodyMounted Wireless Communication Devices-Human Models, Instrumentation, and Procedures-Part 2: Procedure to Determine the Specific Absorption Rate (SAR) for Mobile Wireless Communication Devices Used in Close Proximity to the Human Body (Frequency Range of $30 \mathrm{MHz}$ to 6 GHz), Draft, IEC Standard 62209-2, Jul. 2007.

[38] A. Drossos, V. Santomaa, and N. Kuster, "The dependence of electromagnetic energy absorption upon human head tissue composition in the frequency range of 300-3000 MHz," IEEE Trans. Microw. Theory Tech., vol. 48, no. 11, pp. 1988-1995, Nov. 2000.

[39] A. Christ, A. Klingenböck, T. Samaras, C. Goiceanu, and N. Kuster, "The dependence of electromagnetic far-field absorption on body tissue composition in the frequency range from $300 \mathrm{MHz}$ to $6 \mathrm{GHz}$," IEEE Trans. Microw. Theory Tech., vol. 54, no. 5, pp. 2188-2195, May 2006.

[40] M. G. Douglas and C.-K. Chou, "Enabling the use of broadband tissue equivalent liquids for specific absorption rate measurements," in Proc. IEEE Electromagn. Compat. Symp., Honolulu, HI, Jul. 2007, pp. 1-6.

[41] Federal Communications Commission Office of Engineering and Technology Supplement C (Ed. 01-01) to OET Bulletin 65 (ed. 97-01), Evaluating Compliance With FCC Guidelines for Human Exposure to Radiofrequency Electromagnetic Fields, Additional Information for Evaluating Compliance of Mobile and Portable Devices with FCC Limits for Human Exposure to Radiofrequency Emissions, Washington, DC, Jun. 2001.

[42] M. F. Abedin and M. Ali, "Modifying the ground plane and its effect on planar inverted-F antennas (PIFAs) for mobile phone handsets," IEEE Antennas Wireless Propag. Lett., vol. 2, no. 15, pp. 226-229, Feb. 2005.

[43] M. Ali and G. J. Hayes, "Analysis of integrated inverted-F antennas for bluetooth applications," in Proc. IEEE Antennas Propag. Conf. Wireless Commun. Dig., Waltham, MA, Nov. 2000, pp. 21-24.

[44] D. M. Pozar, Microwave Engineering, 2nd ed. New York: Wiley, 1998, pp. 300-306.

[45] W. Geyi, "A method for the evaluation of small antenna Q," IEEE Trans. Antennas Propag., vol. 51, no. 8, pp. 2124-2129, Aug. 2003.

[46] Zeland Software, Freemont, CA. IE3D User's Guide [Online]. Available: http://www.zeland.com/

[47] Remcom Inc, State College, PA. XFDTD User's Guide [Online]. Available: http://www.remcom.com/

[48] P. Dimbylow, M. Khalid, and S. Mann, "Assessment of specific energy absorption rate (SAR) in the head from a TETRA handset," Phys. Med. Biol., vol. 48, pp. 3911-3926, Nov. 2003.

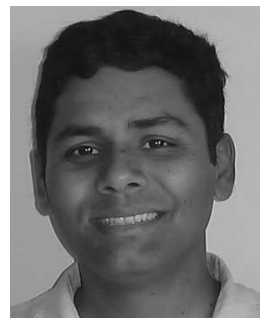

Abu T. M. Sayem received the B.Sc. degree in electrical and electronic engineering from Bangladesh University of Engineering and Technology, Dhaka, Bangladesh, in 1999, and the M.Eng. and Ph.D. degrees in electrical engineering from the University of South Carolina, Columbia, both in 2007.

From February 2000 to October 2000, he was with Ekushey Television, Ltd., and from November 2000 to August 2003, he was an RF engineer at GrameenPhone, Ltd., Dhaka. In 2008, he joined Motorola, Inc., Libertyville, IL, where he is currently engaged in research on antenna design for cellular phones. He is the author or coauthor of several journal articles, conference papers, and one book chapter. His current research interests include miniature antennas, ultra-wideband antennas and bioelectromagnetics.

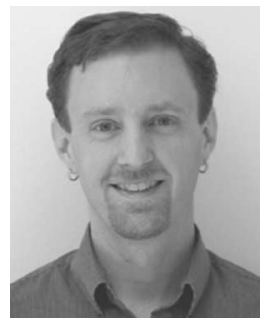

Mark G. Douglas (S'86-M'98-SM'05) received the B.Eng degree from the University of Victoria, Victoria, BC, Canada, in 1990, the M.Sc. degree from the University of Calgary, Calgary, AB, Canada, in 1993, and the Ph.D. degree from the University of Victoria in 1998, all in electrical engineering. His master's thesis concerned the development of compact, high-performance diversity antennas in wireless communications. His doctoral dissertation concerned the use and development of numerical modeling to study the electromagnetic interaction between handheld wireless devices and the user

From 1998 to 2002, he was a Senior Technical Leader with the Antenna Development Group, Ericsson Inc., Research Triangle Park, NC, and a member of the Ericsson EMF Research Group, Stockholm, Sweden, where he was engaged in research in antenna design and RF dosimetry. In 2002, he joined the Motorola Corporate EME Research Laboratory in Fort Lauderdale, FL, where he is currently a Distinguished Member of the Technical Staff. His current research interests include radiofrequency dosimetry. He is the author or coauthor of 40 refereed journal and conference papers. He is the holder of five patents.

Dr. Douglas is a member of the Bioelectromagnetics Society. He is the Chair of the IEEE International Committee on Electromagnetic Safety, Technical Committee 34, and Subcommittee 1, and a contributing member of the International Electrotechnical Committee, Project Team 62209, both concerning the development of SAR measurement standards. He has reviewed several papers for the IEEE TRANSACTIONS ON ANTENNAS AND PROPAGATION, the IEEE TRANSACTIONS ON ElECTROMAGNETIC COMPATIBILITY, and the IEEE TRANSACTIONS ON MICROWAVE THEORY AND TECHNIQUES.

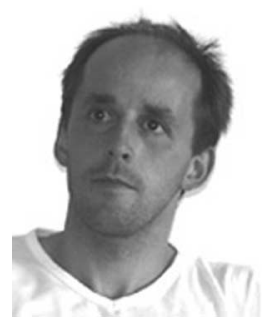

Gernot Schmid was born in Vienna, Austria, in 1969. He received the M.Sc. degree in electrical engineering from Technical University of Vienna, Vienna, where since 2006, he is working toward the Ph.D. degree in electrical engineering.

In 1997, he joined the Austrian Research Centers, where he was engaged in research in the field of experimental and numerical RF dosimetry and led numerous national and international research projects. Since 2002, he is the Deputy Head of the business unit Mobile Communications Safety of the Austrian Research Centers. He is author or coauthor of 14 refereed journal papers and more than 60 conference papers. His current research interests include the interaction of electromagnetic fields with biological tissue and the development of methods for representative exposure assessment. 


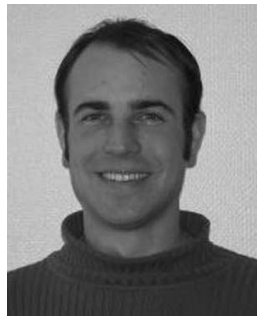

Ben Petric was born in Lower Austria in 1979. He received the Engineering degree in communication engineering from the Engineering School Moedling, Moedling, Austria, in 1999.

In 2000, he joined the Austrian Research Centers, as an RF Measurement Engineer in the field of antenna calibration and international site evaluations of anechoic chambers. Since 2005, he is with the business unit Mobile Communications Safety of the Austrian Research Centers, where he has been involved in several national and international research projects related to exposure assessment in electromagnetic fields. He is the coauthor of several journal articles and conference papers. His current research interests include the improvement of measurement methodologies in RF exposure assessment.

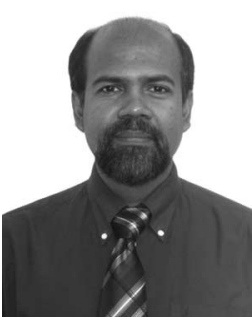

Mohammod Ali (M'93-SM'03) received the B.Sc. degree in electrical and electronic engineering from Bangladesh University of Engineering and Technology, Dhaka, Bangladesh, in 1987, and the M.A.Sc. and $\mathrm{Ph} . \mathrm{D}$. degrees from the University of Victoria, Victoria, BC, Canada, in 1994 and 1997, respectively, both in electrical engineering.

He was with the Bangladesh Institute of Technology, Chittagong, Bangladesh, from 1988 to 1992 From January 1998 to August 2001, he was with Ericsson Inc., Research Triangle Park, NC. Since August 2001, he has been with the Department of Electrical Engineering, University of South Carolina, Columbia, where he is currently an Associate Professor. He had also held appointments as a Visiting Research Scientist with the Motorola Corporate EME Research Laboratory, Plantation, FL, during June to August 2004. He established the Microwave Engineering Laboratory at the University of South Carolina in 2001. He has served as a Reviewer and Panelist for grant proposals for a number of federal and local funding agencies. He is the author or coauthor of more than 100 publications. He is the holder of several patents. His current research interests include miniaturized packaged (embedded) antennas, metamaterials and their antenna applications, distributed wireless sensors and rectennas, and portable/wearable antennas and their interactions with humans (SAR).

Dr. Ali has served as a member of the Technical Program Committee for the IEEE Antennas and Propagation Society's International Symposium in 2006 and 2008. He was also a member of the Technical Program Committee for the IEEE International Workshop on Antenna Technology in 2005. He regularly reviews papers for the IEEE TRANSACTIONS ON ANTENNAS AND PROPAGATION, the IEEE TRANSACTIONS ON MicrowaVE THEORY AND TECHNIQUES, the IEEE TRANSACTIONS ON ELECTROMAGNETIC COMPATIBILITY, and a number of other journals. Currently, he is the Technical Program Co-Chair for the 2009 IEEE Antennas and Propagation Society's International Symposium to be held in Charleston, SC. He is an Associate Editor for the IEEE ANTENNAS AND Wireless Propagation LetTERs. He was the recipient of the 2003 National Science Foundation Faculty Career Award. He was also the recipient of the College of Engineering and Information Technology Young Investigator Award from the University of South Carolina in 2006. 